\title{
Distinct states of proinsulin misfolding in MIDY
}

\section{Leena Haataja ${ }^{1}$, Anoop Arunagiri ${ }^{1}$, Anis Hassan ${ }^{1}$, Kaitlin Regan', Billy Tsai ${ }^{2}$, Balamurugan Dhayalan $^{3}$, Michael A. Weiss ${ }^{3}$, Ming Liu ${ }^{1,4}$, and Peter Arvan*1}

From: ${ }^{1}$ The Division of Metabolism, Endocrinology \& Diabetes and ${ }^{2}$ Department of Cell \& Developmental Biology, University of Michigan Medical Center, Ann Arbor MI 48105; ${ }^{3}$ Department of Biochemistry and Molecular Biology, Indiana University, Indianapolis, IN 46202; ${ }^{4}$ Department of Endocrinology and Metabolism, Tianjin Medical University General Hospital, Tianjin 300052, China

*To whom correspondence may be addressed:

Peter Arvan MD PhD ORCID ID: (iD) http://orcid.org/0000-0002-4007-8799 Division of Metabolism, Endocrinology \& Diabetes, University of Michigan, Brehm Tower rm 5112

1000 Wall St. Ann Arbor, MI 48105

email: parvan@umich.edu

FAX: 734-232-8162

Running Title. Proinsulin Disulfide Mispairing

Key Words. endoplasmic reticulum, disulfide bonds, protein trafficking, insulin, diabetes

Abbreviations. ER, endoplasmic reticulum; MIDY, Mutant INS-gene induced Diabetes of Youth 


\begin{abstract}
A precondition for efficient proinsulin export from the endoplasmic reticulum (ER) is that proinsulin meets ER quality control folding requirements, including formation of the Cys(B19)-Cys(A20) "interchain" disulfide bond, facilitating formation of the Cys(B7)-Cys(A7) bridge. The third proinsulin disulfide, Cys(A6)-Cys(A11), is not required for anterograde trafficking, i.e., a "lose-A6/A11" mutant [Cys(A6), Cys(A11) both converted to Ser] is well secreted. Nevertheless, an unpaired Cys(A11) can participate in disulfide mispairings, causing ER retention of proinsulin. Among the many missense mutations causing the syndrome of Mutant INS gene-induced Diabetes of Youth (MIDY), all seem to exhibit perturbed proinsulin disulfide bond formation. Here we have examined a series of seven MIDY mutants [including G(B8)V, Y(B26)C, L(A16)P, H(B5)D, V(B18)A, R(Cpep+2)C, E(A4)K], six of which are essentially completely blocked in export from the ER in pancreatic $\beta$-cells. Three of these mutants, however, must disrupt the Cys(A6)-Cys(A11) pairing to expose a critical unpaired cysteine thiol perturbation of proinsulin folding and ER export, because when introduced into the proinsulin lose-A6/A11 background, these mutants exhibit native-like disulfide bonding and improved trafficking. This maneuver also ameliorates dominant-negative blockade of export of co-expressed wild-type proinsulin. A growing molecular understanding of proinsulin misfolding may permit allele-specific pharmacological targeting for some MIDY mutants.
\end{abstract}




\section{Introduction}

Patients bearing autosomal dominant diabetogenic mutations in the INS gene [1,2] develop a syndrome referred to as Mutant INS gene-induced Diabetes of Youth [MIDY [3-5]; alternative designations include non-autoimmune type 1 diabetes, MODY10 [6, 7] (OMIM \#613370), as well as other names [8]]. MIDY mutations cause proinsulin misfolding in the endoplasmic reticulum (ER) [1,9]; moreover, MIDY mutants directly associate with wild-type (WT) "bystander" proinsulin, thereby imposing impaired ER exit onto those molecules as well [10-15].

Pancreatic $\beta$-cells can synthesize $>6000$ new proinsulin molecules/second [16]. To achieve insulin bioactivity, proinsulin must form three native disulfide bonds: Cys(B7)-Cys(A7), Cys(B19)-Cys(A20), and Cys(A6)-Cys(A11) [17] (Fig. 1); thus the $\beta$-cell ER supports formation $\geq 18,000$ disulfide bonds/second, designed to accommodate physiological levels of insulin production [5]. However, whereas three native disulfide bonds are required for the ultimate bioactivity of insulin, only two of these bonds are needed for proinsulin export from the ER [18]. Indeed, we developed a proinsulin mutant known as "lose-A6/A11" which rapidly forms the two native disulfide bonds [Cys(B7)-Cys(A7) and Cys(B19)-Cys(A20)], undergoes intracellular transport, and localizes to secretory granules in $\beta$-cells - this variant is secreted with an efficiency comparable to that of WT proinsulin [19]. On the other hand, we also recognize that MIDY mutant mice bearing the heterozygous Ins2-Munich allele - encoding proinsulin-C(A6)S develop severe insulin-deficient diabetes [20], indicating that an unpaired proinsulin-Cys(A11) creates an impediment to proinsulin trafficking through disulfide mispairings [21] that can result in catastrophic proinsulin misfolding [19].

Distinct MIDY mutant alleles are associated with diabetes onset ranging from neonatal life through adulthood $[2,8]$. In the current study, we sought to determine whether Cys residues from the A6/A11 tandem might contribute to proinsuiln failure in MIDY. Here, we provide evidence for two main subsets of misfolded MIDY mutants that we propose are distinguished by their competence in forming the Cys(A6)-Cys(A11) disulfide. In one subset, impaired closure of the Cys(A6)-Cys(A11) bridge leads directly to aberrant intermolecular disulfide-linked complexes, blocking proinsulin export from the ER and dominantly retaining co-expressed WT proinsulin. 


\section{METHODS}

\section{Materials, Antibodies, and Human Insulin Immunoassay}

See Resources Table. We make special note that the manufacturer indicates that the human insulin STELLUX ELISA assay (ALPCO 80-INSHU-CH01) has a cross-reactivity with human insulin of 100\%; human proinsulin undetectable; mouse insulin undetectable; rat insulin-1 $0.49 \%$, and rat insulin-2 undetectable.

\section{Plasmids encoding mutant proinsulins}

Plasmids encoding myc-tagged human proinsulin, myc-tagged human "lose-A6/A11" proinsulin and hProCpepSfGFP (Resources Table) were used as templates for mutagenesis using the QuikChange site-directed mutagenesis kit, with resulting plasmids confirmed by direct DNA sequencing.

\section{Cell Culture and transfection: 293T, INS832/13, and Min6 cells}

INS832/13 cells (see Key Resources Table) were cultured in RPMI-1640 medium supplemented with 10\% FBS, $1 \mathrm{mM}$ sodium pyruvate, $0.05 \mathrm{mM} \quad \beta$-mercaptoethanol, $10 \mathrm{mM}$ HEPES $\mathrm{pH} 7.35$, and penicillin/streptomycin. Min6 cells (see Key Resources Table) were cultured in DMEM (25 mM glucose) supplemented with 10\% FBS, $1 \mathrm{mM}$ sodium pyruvate, $0.1 \mathrm{mM} \quad \beta$-mercaptoethanol, and penicillin/streptomycin. 293T cells (see Key Resources Table) were cultured in DMEM supplemented with $10 \%$ calf serum and penicillin/streptomycin. Cells were transfected with lipofectamine (ThermoFisher Scientific).

\section{SDS-PAGE and Western blotting}

At 24 or 48 h post-transfection, cells were washed with PBS and lysed in Laemmli sample buffer or RIPA buffer (10 mM Tris $\mathrm{pH}$ 7.4, $150 \mathrm{mM} \mathrm{NaCl}, 0.1 \%$ SDS, 1\% NP40, $2 \mathrm{mM}$ EDTA) including protease/phosphatase inhibitor cocktail (Sigma-Aldrich). Samples were resolved by SDS-PAGE in 4-12\% Bis-Tris NuPAGE gels under either nonreducing or reducing conditions. Completed nonreducing gels were incubated in $30 \mathrm{mM}$ dithiothreitol (DTT) for $10 \mathrm{~min}$ at room temperature prior to electrotransfer to nitrocellulose. Development of immunoblots used enhanced chemiluminescence, captured with a Fotodyne gel imager, quantified using ImageJ.

\section{Metabolic labeling, immunoprecipitation, and Tris-tricine-urea-SDS-PAGE}

Transfected INS832/13 were incubated in media lacking Cys and Met for $30 \mathrm{~min} ;{ }^{35} \mathrm{~S}$-pulse-labeled for 10 - 30 min at $37^{\circ} \mathrm{C}\left(\operatorname{Tran}^{35} \mathrm{~S}\right.$ label, Perkin Elmer) and chased in complete growth media; at chase time, media 
were collected. Before lysis, cells were washed with ice-cold PBS containing $20 \mathrm{mM}$ N-ethyl maleimide (NEM), and then lysed in RIPA buffer (25 mM Tris, pH 7.5, $100 \mathrm{nM} \mathrm{NaCl,} 1 \%$ Triton X-100, 0.2\% deoxycholic acid, 0.1\% SDS, $10 \mathrm{mM}$ EDTA) [or, in Fig. 7C, $10 \mathrm{mM}$ Tris pH 7.4, $150 \mathrm{mM} \mathrm{NaCl,} \mathrm{1 \%} \mathrm{NP-}$ 40, 0.1\% SDS, $2 \mathrm{mM}$ EDTA] containing $2 \mathrm{mM} \mathrm{NEM}$ and a protease inhibitor cocktail. Cell lysates, normalized to trichloroacetic acid-precipitable counts, were pre-cleared with pansorbin and immunoprecipitated with anti-Myc, anti-insulin, or anti-GFP antibodies and protein A-agarose overnight at $4^{\circ} \mathrm{C}$. Immunoprecipitates were analyzed by nonreducing / reducing Tris-tricine-urea-SDS-PAGE, or 4$12 \%$ gradient Nu-PAGE. Gels were fixed and dried, followed by phosphorimaging or autoradiography; bands were quantified using ImageJ.

\section{Live cell Microscopy of GFP-tagged proinsulins}

Transfected INS832/13 cells were cultured in LabTek-II coverglass chambers (Nunc). At $24 \mathrm{~h}$ posttransfection live cell fluorescence was examined using a Nikon A1 Confocal Microscope. Multiple image/fields were captured for each construct; raw images were processed using NIS-Elements Viewer 5.21 software.

\section{ER stress response as measured by BiP-Luciferase}

Cells were co-transfected with plasmids encoding human proinsulin construct, BiP promoter-firefly luciferase reporter, and renilla luciferase, at a DNA ratio of 100:10:1. At $48 \mathrm{~h}$ post-transfection, cells were lysed and analyzed for firefly luciferase normalized to renilla luciferase activity (Promega Dual Luciferase assay).

\section{Statistical Analysis}

Results were calculated as mean \pm s.d.. Statistical analyses employed two-tailed unpaired Student's $t$-test (Figs. 3B, 7E), or one-way ANOVA followed by Dunnett's for multiple comparisons to WT (Figs. 3C, 4B, 4D, 8C, S2, S3 ), or Tukey's test for multiple comparisons between all samples (Figs. 6B, 6E, S4), using GraphPad Prism v.8. A $p$-value of $<0.05$ was taken as significant.

\section{Structural Modeling}

Spatial relationships in native insulin were examined in the wild-type zinc insulin hexamer (Protein Databank [PBD] entry 4INS, from the insulin hexamer) $[22,23]$. This structure contains an asymmetric dimer (TT') in the asymmetric unit. Structural elements were visualized using InsightII and Pymol.

\section{Data and Resource Availability}


Data generated and analyzed during this study are included in the published article (and its online supplementary files). Additional data generated during the current study are available from the corresponding author upon reasonable request. 


\section{RESULTS}

\section{The effect of MIDY mutations on proinsulin folding and export}

In this study, we have examined MIDY mutants producing autosomal-dominant neonatal diabetes, including H(B5)D [7], a previously unreported G(B8)V, Y(B26)C and L(A16)P [24], and the commonly reported $\mathrm{R} 89 \mathrm{C}$ [which has a polypeptide position $\mathrm{R}(\mathrm{Cpep}+2) \mathrm{C}$ ] [25], as well as two mutants producing diabetes at somewhat later ages including V(B18)A [26] and E(A4)K [27]. Most MIDY missense mutants fall within the established primary structure of mature human insulin. Fig. 1A highlights the degree of natural sequence variation at each position [28]; Figs. 1B, C show the site of these MIDY residues in the 2-chain insulin structure. Unsurprisingly, MIDY mutations tend to occur at sites of residue conservation, indicating evolutionary intolerance for substitution. Although the C-peptide and its flanking cleavage sites are not shown, we note that $\mathrm{R}(\mathrm{Cpep}+2) \mathrm{C}$ replaces a highly conserved Arg at the C-peptide/A-chain cleavage site with an extra $\left(7^{\text {th }}\right)$ cysteine that, by definition, has no natural disulfide partner.

Each MIDY mutant was engineered into the hPro-CpepMyc cDNA encoding human proinsulin bearing myc-tagged C-peptide [12]. When expressed heterologously in $293 \mathrm{~T}$ cells, the construct bearing the WT insulin chains was secreted to the medium, in contrast with any of the 7 MIDY mutants (Fig. 2A; quantified in Fig. 2C). Moreover, WT human proinsulin expression allowed for secretion of co-expressed WT mouse proinsulin (detected with a species-specific proinsulin mAb), whereas each of the MIDY mutants yielded a "bystander effect" [11, 29], inhibiting the secretion of co-expressed WT proinsulin (Fig. 2B).

The abundance of expression of WT proinsulin, or other factors ongoing in $\beta$-cells, can subvert the efficiency of ER quality control, leading to escape of a subset misfolded proinsulin molecules from the ER [14]. With this in mind, we expressed MIDY proinsulins in Min6 (mouse) $\beta$-cells — using the myc-tag to unequivocally distinguish transfected from endogenous proinsulin. WT human proinsulin was abundantly exported in Min6 cells, being secreted as unprocessed proinsulin (Fig. 3A) and being converted intracellularly to human insulin (Fig. 3B). Whereas all MIDY mutants were significantly impaired in export (Fig. 3C), there was demonstrable low-level secretion of several MIDY mutants, notably including proinsulin-V(B18)A (Fig. 3A, C). We could independently confirm some intracellular transport of proinsulin-V(B18)A by detection of processed human insulin in these mouse $\beta$-cells (Supplemental Fig. $\mathrm{S} 1)$, indicating that $\mathrm{V}(\mathrm{B} 18) \mathrm{A}$ was in small part able to reach immature secretory granules for proinsulin-toinsulin conversion [30,31]. 
Using nonreducing Tris-tricine-urea-SDS-PAGE to discern the formation of native B-A-chain disulfide bonds within newly-synthesized proinsulin [19], we examined the oxidation of myc-tagged human proinsulins expressed in INS832/13 $\beta$-cells. Whereas newly-synthesized WT proinsulin predominantly formed native disulfide bonds, this was impaired in 6 of the 7 MIDY mutants (Fig. 4A, B). Newlysynthesized MIDY mutants were, once again, significantly impaired in their secretion from $\beta$-cells (Fig. $4 C, D)$. Interestingly, proinsulin- $\mathrm{R}(\mathrm{Cpep}+2) \mathrm{C}$ exhibited native-like oxidation [Figs. 4A; bearing in mind an extra $\left(7^{\text {th }}\right)$ cysteine exposed on the proinsulin surface, based upon its location at the cleavage site]; nevertheless it exhibited severely defective secretion (Fig. 4C, D).

\section{MIDY proinsulins engage in intermolecular disulfide mispairing in the ER of $\beta$-cells}

We recently found that proinsulin in pancreatic $\beta$-cells is susceptible to forming intermolecular disulfidelinked complexes, and an increased abundance of these aberrant complexes precedes the onset of diabetes [32]. In lysates of Min6 cells transfected to express myc-tagged human proinsulin or MIDY mutants, we looked for the presence of proinsulin disulfide-linked complexes (resolved by nonreducing SDS-PAGE and detected by human-specific proinsulin immunoblotting). Reducing SDS-PAGE (in which intermolecular disulfide-linked proinsulin runs as reduced monomers) was used to detect total human proinsulin levels in the cells. By nonreducing SDS-PAGE, whereas WT myc-tagged human proinsulin was predominantly monomeric, the various MIDY mutants formed an increased fraction of disulfidelinked dimers and higher molecular weight complexes (Fig. 5A). By analysis using two different proinsulin antibodies, we were able to calculate a misfolding index indicating increased disulfide-linked complex formation for at least three (and probably all) of the MIDY proinsulin mutants (Supplemental Fig. S2). Moreover, there was a suggestion of increased ER stress induced by most MIDY mutants [response measured by BiP-luciferase assay, although only L(A16)P generated statistical significance (Supplemental Fig. S3)].

\section{Impact of cysteines A6 and A11 on MIDY proinsulin folding and export}

A proinsulin double mutant known as lose-A6/A11 (bearing Cys-to-Ser substitutions) exhibits essentially normal intracellular trafficking in $\beta$-cells; thus, MIDY mutants retained by virtue of an unpaired Cys(A11) [19] might be rescued in a lose-A6/A11 background. We immediately observed significantly rescued secretion of $\mathrm{H}(\mathrm{B} 5) \mathrm{D}, \mathrm{R}(\mathrm{Cpep}+2) \mathrm{C}$, and $\mathrm{E}(\mathrm{A} 4) \mathrm{K}$ [and a trend of increased secretion for $\mathrm{V}(\mathrm{B} 18) \mathrm{A}$ ] (Fig. $6 \mathrm{~A}, \mathrm{~B})$ in Min6 $\beta$-cells, but no important benefit to other MIDY mutants $\mathrm{G}(\mathrm{B} 8) \mathrm{V}, \mathrm{L}(\mathrm{A} 16) \mathrm{P}$, and not 
significant effect for Y(B26)C (Fig. 6A, B). Nevertheless, most newly-synthesized MIDY mutants now exhibited a trend of an increased fraction of near-native oxidized forms (Fig. 6C; compare to Fig. 4A), and this was statistically significant for two of the mutants that exhibited secretion rescue [H(B5)D and E(A4)K (Supplemental Fig. S4)]. However, despite this indication of improved oxidation in $\beta$-cells - on repeated analysis, while improvement of export of newly-synthesized MIDY mutants in the lose-A6/A11 background was observed for $\mathrm{H}(\mathrm{B} 5) \mathrm{D}, \mathrm{R}(\mathrm{Cpep}+2) \mathrm{C}, \mathrm{E}(\mathrm{A} 4) \mathrm{K}$ [and a trend to increased secretion for $\mathrm{V}(\mathrm{B} 18) \mathrm{A}]$, there was no significantly enhanced export for G(B8)V, Y(B26)C, or L(A16)P (Fig. 6D, E). [Identical results were obtained upon expression of these constructs in 293T cells, not shown.]

Interestingly, whereas lose-A6/A11 improved oxidation of most of the MIDY mutants as noted above, MIDY proinsulin mutants G(B8)V, Y(B26)C, or L(A16)P — recovered well by reducing SDS-PAGE were caught up primarily in intermolecular disulfide-linked complexes rather than proinsulin monomers (Fig. 5B). Remarkably however, the lose-A6/A11 background appreciably rescued detectable intracellular proinsulin monomers for $\mathrm{H}(\mathrm{B} 5) \mathrm{D}, \mathrm{R}(\mathrm{Cpep}+2)$, and $\mathrm{E}(\mathrm{A} 4) \mathrm{K}$, as well as $\mathrm{V}(\mathrm{B} 18) \mathrm{A}$ (Fig. 5B). These data strongly suggest that these latter MIDY mutations inhibit the pairing of Cys(A6) and Cys(A11), leading to their engagement in inappropriate intermolecular disulfide bond formation (which is improved in the loseA6/A11 background).

When expressed either in pancreatic $\beta$-cell lines or in $\beta$-cells in vivo, a construct known as hProCpepSfGFP (bearing a superfolder-GFP within the C-peptide of human proinsulin) tends to accumulate in the juxtanuclear Golgi region and becomes stored as processed fluorescent C-peptide in mature secretory granules [13, 33]. With this in mind, we examined each of the previously noted MIDY mutants in an otherwise WT or lose-A6/A11 proinsulin background in INS832/13 $\beta$-cells. In the absence of mutations causing MIDY, both proinsulin and lose-A6/A11 were delivered to punctate secretory granules at the $\beta$ cell periphery; and each of the MIDY mutations introduced into the otherwise WT proinsulin background exhibited a cytoplasmic reticular distribution classic for the ER (Fig. 7A and Supplemental Fig. S5). In conjunction with this, WT proinsulin could be seen to be cleaved (albeit weakly) to a conversion intermediate and fully processed SfGFP-tagged C-peptide, and this was not obvious for the MIDY mutants (Fig. 7B upper panel, green arrow). When introduced into the lose-A6/A11 background, the MIDY mutations $\mathrm{Y}(\mathrm{B} 26) \mathrm{C}, \mathrm{G}(\mathrm{B} 8) \mathrm{V}$, and L(A16)P continued to exhibit a classic ER-like distribution, whereas $\mathrm{H}(\mathrm{B} 5) \mathrm{D}, \mathrm{R}(\mathrm{Cpep}+2) \mathrm{C}$, and E(A4)K each reverted to a granule pattern (Fig. 7A and Supplemental Fig. S5). In conjunction with this, the latter three MIDY mutants also yielded processed GFP-tagged C-peptide (Fig. 7B lower panel, green arrows). [As an aside, the common $\mathrm{R}(\mathrm{Cpep}+2) \mathrm{C}$ mutation mutates the C-A junctional cleavage site, and the cleavage intermediate band generated from this construct exhibited a 
unique, abnormal mobility, suggesting an atypical cleavage (Fig. 7B).] Additionally, the V(B18)A mutation yielded a hint of processed C-peptide in both the WT and lose-A6/A11 background (Fig. 7B) and in counting multiple transfected cell images, some green fluorescent secretory granules were detected, albeit decreased by $>70 \%$. Taken together, these morphological and biochemical findings support the characterization of two main subgroups of MIDY mutants that can either be rescued or not-significantlybenefitted by the lose-A6/A11 substitutions, respectively, while V(B18)A behaves as a slightly better tolerated MIDY mutation.

As the $\mathrm{G}(\mathrm{B} 8) \mathrm{V}$ mutation had not been described previously (we learned of this spontaneous mutation in a New Zealand girl who presented with diabetes at 6 weeks of age), we directly compared newlysynthesized G(B8)V with G(B8)S in the lose-A6/A11 background when these constructs were expressed in $293 \mathrm{~T}$ cells. Whereas the lose-A6/A11 parent protein rapidly formed a near-native oxidized form and underwent significant secretion within an hour after synthesis, both $G(B 8) V$ and $G(B 8) S$ appeared identical, with impaired oxidation and no detectable secretion to the medium (Supplemental Fig. S6). We further examined the $\mathrm{G}(\mathrm{B} 8) \mathrm{V}$ mutation in the hPro-CpepSfGFP background by pulse-chase radiolabeling of the transfected cells, followed by immunoprecipitation with anti-GFP. Immediately post-pulse, recovery of newly-synthesized G(B8)V mutant was less than from cells expressing WT hPro-CpepSfGFP, and both constructs could be detected in disulfide-linked complexes (Fig. 7C, D). By 90 min of chase, however, WT hPro-CpepSfGFP could be recovered in the medium while its intracellular level had fallen (Fig. 7D, E). In contrast for the G(B8)V mutant at $90 \mathrm{~min}$ of chase, there was no secretion and its intracellular level had not declined; in fact its intracellular level was now $>$ that of WT hPro-CpepSfGFP (Fig. 7D, E), although almost none of the newly-synthesized mutant protein could be recovered as proinsulin monomers by nonreducing SDS-PAGE (Fig. 7C) - indicative of a severe MIDY mutation.

\section{Impact of cysteines A6 and A11 on dominant-negative MIDY behavior}

To test dominant-negative blockade of WT proinsulin, we co-expressed in $293 \mathrm{~T}$ cells each human myctagged MIDY mutant in the lose-A6/A11 background, with untagged WT mouse proinsulin. We could then look independently by Western blotting at the export of the lose-A6/A11 MIDY constructs (anti-myc immunoblotting) and WT proinsulin (mAb anti-rodent proinsulin). We observed negligible secretion of G(B8)V, Y(B26)C, and L(A16)P in the lose-A6/A11 background (Fig. 8A; quantified in Fig. 8C), accompanied by suppressed escape of co-expressed WT proinsulin (Fig. 8B). In contrast, we detected significant secretion of $\mathrm{H}(\mathrm{B} 5) \mathrm{D}, \mathrm{R}(\mathrm{Cpep}+2) \mathrm{C}$, and $\mathrm{E}(\mathrm{A} 4) \mathrm{K}$ in the lose-A6/A11 background (Fig. 8A; quantified in Fig. 8C) accompanied by secretion of co-expressed WT proinsulin (Fig. 8B). These data 
suggest that the same proinsulin mutants that are themselves less susceptible to ER quality control are also less effective in trans-dominant blockade of co-expressed WT proinsulin. Indeed, when comparing to Figure 2, none of the lose-A6/A11 MIDY constructs except for L(A16)P are as efficient in blocking coexpressed WT proinsulin, including V(B18)A which itself appears blocked yet cannot efficiently block the trafficking of co-expressed WT proinsulin. Thus the data highlight the potential importance of unpaired Cys(A11) and Cys(A6) in adverse proinsulin folding and trafficking. 


\section{DISCUSSION}

MIDY is disease of protein misfolding causing autosomal dominant diabetes. MIDY mutations threaten native proinsulin disulfide bond formation $[12,19]$. ER quality control recognizes and prevents export of misfolded proinsulin, thus MIDY mutants have loss of function in generating insulin $[4,5]$. Moreover, natural self-association properties of proinsulin enable the defective MIDY gene product to associate with and dominantly block export of WT proinsulin [10,11,34]. Nevertheless, different MIDY mutations lead to different ages of diabetes onset, suggesting greater or lesser severity of proinsulin misfolding [4, 35]. In this study, we've examined seven MIDY proinsulin mutants by testing for the importance of Cys(A6) and Cys(A11) because, curiously, these residues normally engage in an intramolecular disulfide bond that is nonessential for proinsulin trafficking $[18,19]$ yet in MIDY they may participate in intermolecular disulfide bonds that could render mutant proinsulin molecules unacceptable to ER quality control.

\section{MIDY mutants exhibit a range of trafficking defects}

Proinsulin-V(B18)A is linked to diabetes onset beyond the neonatal period [ages 3.3 - 10.5 years [26]]. Although interchange of Val-to-Ala is a conservative substitution that is generally well-tolerated [36], protein context is important in determining pathogenicity, as some similar missense substitutions are linked to disease [37]. Equally important is cellular context: we did not detect anterograde trafficking of proinsulin-V(B18)A from $293 \mathrm{~T}$ cells even in the lose-A6/A11 background (Fig. 8), yet low-level anterograde trafficking was observable in pancreatic $\beta$-cells (Fig. 3), even leading to the formation of small quantities of mature human insulin (Supplemental Fig. S1). These data suggest that the V(B18)A mutant exhibits a slightly less severe proinsulin misfolding than a number of other MIDY mutants.

\section{Defective Cys(A6)-Cys(A11) pairing defines two subgroups of mutations}

The MIDY mutants G(B8)V, Y(B26)C, and L(A16)P exhibited significantly less anterograde trafficking than WT proinsulin, and even less than the MIDY mutant proinsulin-V(B18)A. The trafficking defect of the newly-described proinsulin- $\mathrm{G}(\mathrm{B} 8) \mathrm{V}$ is severe and very similar to that of the $\mathrm{G}(\mathrm{B} 8) \mathrm{S}$ mutation (Supplemental Fig. S6), which has been recently described to account for spontaneous diabetes in the KINGS diabetic mouse [38], as well as being one of the first described human MIDY mutants [25] — its folding defect is considered further, below. Additionally, it might be predicted that proinsulin-Y(B26)C and L(A16)P (also discussed further, below) would be catastrophically detrimental to folding as they (in addition to position B8) fall among the more conserved residues within insulin (Fig. 1A) — and patients 
bearing these heterozygous mutations have been found to be insulin-requiring within the first 6 months of life [24]. In 293T cells, these mutants could not be secreted either in the proinsulin or lose-A6/A11 background (Figs. 2, 8); moreover, secretion was profoundly low in pancreatic $\beta$-cells (Fig. 3), and could not be statistically increased in the lose-A6/A11 background in either Min6 or INS832/13 cells (Figs. 6, 8).

In contrast with the foregoing proinsulin mutants, we find that MIDY mutations encoding H(B5)D, $\mathrm{R}(\mathrm{Cpep}+2) \mathrm{C}$, or E(A4)K fall into a distinct group. Specifically, whereas these mutants cannot be secreted in the proinsulin backgound, they are all exported to a greater degree in the lose-A6/A11 background able to be secreted (Fig. 6) and to be processed to mature C-peptide in pancreatic $\beta$-cells (Fig. 7).

Recovery of export in the lose-A6/A11 background can be accounted for by diminished formation of intermolecular disulfide-linked complexes (Fig. 5). As this particular subgroup of MIDY mutants develops improved folding in the lose-A6/A11 background, leading to improved trafficking in $\beta$-cells, we conclude that for this subset of MIDY proinsulin mutants, burying these cysteines in the Cys(A6)Cys(A11) disulfide bond makes them unavailable for intermolecular disulfide mispairing [19]. Rescue in the lose-A6/A11 background then allows unperturbed initial formation of the Cys(B19)-Cys(A20) disulfide, leaving driving the remaining $\mathrm{Cys}(\mathrm{B} 7)$ and $\mathrm{Cys}(\mathrm{A} 7)$ free thiol groups into disulfide partnership [19], eliminating or diminishing the predisposition for intermolecular disulfide bond formation, and that is one of the major factors in ER quality control of proinsulin export.

In the 'T-state' insulin crystal structure [39], the imidazolic ring of H(B5) packs within an interchain near to the Cys(A6)-Cys(A11) disulfide bond (Supplemental Fig. S7A). We posit that H(B5)D may alter the relative positions and solvation of $\mathrm{Cys}(\mathrm{A} 6)$ and $\mathrm{Cys}(\mathrm{A} 11)$ [and to some extent also Cys(A7) [40, 41]]. Additionally, in the solution structure of proinsulin, $\mathrm{R}(\mathrm{Cpep}+2)$ and $\mathrm{E}(\mathrm{A} 4)$ appear to form a salt bridge and may contribute to the 'CA knuckle' [42], which may also help to stabilize the proximal A-chain $\alpha$-helix [43]. In turn, there is a close relationship between proximal A-chain conformation and the Cys(A6)Cys(A11) disulfide bond [44]. (Additionally it seems likely that the extra unpaired cysteine of $\mathrm{R}(\mathrm{Cpep}+2) \mathrm{C}$ might also engage in intermolecular disulfide crosslinking — for which further study is still needed.) Thus, MIDY mutations $\mathrm{H}(\mathrm{B} 5) \mathrm{D}, \mathrm{R}(\mathrm{Cpep}+2) \mathrm{C}$, and $\mathrm{E}(\mathrm{A} 4) \mathrm{K}$ are each expected to perturb the Cys(A6)-Cys(A11) disulfide bond, impacting on ER quality control of proinsulin export, and this may help to explain the beneficial effects of the lose-A6/A11 substitutions.

In contrast, a second subset of MIDY mutants [G(B8)V, Y(B26)C, and L(A16)P] cannot be rescued in the lose-A6/A11 background. G(B8), invariant among vertebrate insulins, insulin-like growth factors (IGFs) 
and relaxins, lacks a side chain but exhibits a critical positive $\phi$ dihedral angle ordinarily forbidden to Lamino acids [23]. From in vitro folding studies, any L-amino-acid substitution in this position predisposes to impaired disulfide pairing [45] as observed for the G(B8)S MIDY mutant [46], triggering permanent neonatal diabetes $[25,38]$. We posit that $\mathrm{G}(\mathrm{B} 8) \mathrm{V}$ similarly enforces an inappropriate negative $\mathrm{B} 8 \phi$ dihedral angle, in turn misorienting the side chain of Cys(B7), which cannot be rescued by the loseA6/A11 template. The side chain of $\mathrm{Y}(\mathrm{B} 26)$ is inserted into a solvent-exposed inter-chain crevice (Supplemental Fig. S7B), and its packing against the conserved nonpolar surface of the central-B-chain $\alpha$ helix bearing L(B11), V(B12) and L(B15) stabilizes a nascent native-like supersecondary structural " $\mathrm{U}$ turn" [23] to promote proper formation of the essential Cys(B19)-Cys(A20) disulfide bond [9, 47], which is likely to be disrupted in the Y(B26)C MIDY mutant - and this too cannot be rescued in the loseA6/A11 background. L(A16) fits snuggly within a potential internal cavity at the confluence of insulin's three native $\alpha$-helices (Supplemental Fig. S7C), and the A16-A19 $\alpha$-helical turn is thought to facilitate alignment with the B-chain $\alpha$-helix to enable initial Cys(B19)-Cys(A20) pairing [47]. The imino-side chain of $\mathrm{P}(\mathrm{A} 16)$ is expected to distort local $\alpha$-helical conformation [48], incurring a local steric clash and destabilizing the internal cavity, leading to an insuperable block to formation of the Cys(B19)-Cys(A20) pairing within proinsulin's folding nucleus [9].

In a slightly milder category from the others, V(B18)A would create a packing defect (Supplemental Fig. S7D) that would be expected to enlarge the range of possible positions/orientations accessible to the adjoining $\mathrm{Cys}(\mathrm{B} 19)$ and its $\mathrm{Cys}(\mathrm{A} 20)$ partner. Evidently, this mutation does not completely preclude Cys(B19)-Cys(A20) pairing (Fig. 3C, Supplemental Fig. S1), with slight secretory improvement by the lose-A6/A11 template (Fig. 6A-C; Supplemental Fig. S5).

Finally, we note that the lose-A6/A11 background resulted in notable diminution of dominant-negative behavior, particularly for the subgroup of MIDY mutants that are themselves rescued in folding and intracellular transport [a modest effect was also observed for Val(B18)A]. These data strongly support the hypothesis that it is the recognition and retention of the misfolded mutant partner by ER quality control that confers ER retention upon the co-expressed WT partner [5]. Indeed there is a definite proinsulinproinsulin partnership, as indicated by the importance of proinsulin dimerization propensity to dominantnegative behavior [34]. Altogether, the findings in this report highlight an improved structural understanding by which proinsulin misfolding might be attacked pharmacologically, a) to block exposure of unpaired cysteines, and b) to limit the increased aberrant proinsulin-proinsulin associations [49] which are a hallmark of MIDY and perhaps also of type 2 diabetes [32]. 


\section{Declarations}

\section{* Ethics approval and consent to participate}

University of Michigan biosafety approval for recombinant DNA: IBCA00001142

* Consent for publication

All co-authors consent

\section{* Availability of data and material}

All primary data and material in the manuscript are available upon reasonable request.

\section{* Competing interests}

There are no competing interests relevant to this article.

\section{* Funding}

This work was supported by primarily by the National Institutes of Health (NIH) R01-DK-48280 and R01DK-111174; and also by NIH R01-DK040949. M.L. is supported by the Natural Science Foundation of China (81830025 and 81620108004) and the National Key R\&D Program of China (2019YFA0802502).

\section{* Authors' contributions}

L.H, A.A., A.H, and K.R. generated research data. P.A. wrote the manuscript. All authors reviewed the manuscript. M.L., B.D., M.A.W., B.T., L.H., A.A. and P.A. revised/edited the manuscript and contributed to discussion.

\section{* Acknowledgements}

The authors thank the University of Michigan Protein Folding Diseases Initiative, and Michigan Diabetes Research Center Imaging core (NIH P30-DK-020572) for assistance with live cell imaging. We thank D. Chatterjee and J. Racca for assistance with molecular graphics.

\footnotetext{
* Authors' information

Peter Arvan MD PhD ORCID ID: ID http://orcid.org/0000-0002-4007-8799
} 


\section{References}

1. Stoy, J., et al., Clinical and molecular genetics of neonatal diabetes due to mutations in the insulin gene. Rev Endocr Metab Disord, 2010. 11(3): p. 205-15.

2. Liu, M., et al., INS-gene mutations: from genetics and beta cell biology to clinical disease. Mol Aspects Med, 2015. 42: p. 3-18.

3. Sun, J., et al., Proinsulin misfolding and endoplasmic reticulum stress during the development and progression of diabetes. Mol Aspects Med, 2015. 42: p. 105-18.

4. Arunagiri, A., et al., Misfolded proinsulin in the endoplasmic reticulum during development of beta cell failure in diabetes. Ann N Y Acad Sci, 2018. 1418(1): p. 5-19.

5. Liu, M., et al., Biosynthesis, structure, and folding of the insulin precursor protein. Diabetes Obes Metab, 2018. 20 Suppl 2: p. 28-50.

6. Molven, A., et al., Mutations in the insulin gene can cause MODY and autoantibody-negative type 1 diabetes. Diabetes, 2008. 57(4): p. 1131-5.

7. Edghill, E.L., et al., Insulin mutation screening in 1,044 patients with diabetes: mutations in the INS gene are a common cause of neonatal diabetes but a rare cause of diabetes diagnosed in childhood or adulthood. Diabetes, 2008. 57(4): p. 1034-42.

8. Barbetti, F., et al., Neonatal Diabetes: permanent neonatal diabetes and transient neonatal diabetes., in Diabetes associated with single gene defects and chromosomal abnormalities., F. Barbetti, L. Ghizzoni, and F. Guaraldi, Editors. 2017, Karger AG: Basel, Switzerland. p. 1-25.

9. Weiss, M.A., Diabetes mellitus due to the toxic misfolding of proinsulin variants. FEBS Lett, 2013. 587(13): p. 1942-50.

10. Liu, M., et al., Proinsulin maturation, misfolding, and proteotoxicity. Proc Natl Acad Sci U S A, 2007. 104: p. 15841-15846.

11. Hodish, I., et al., Misfolded proinsulin affects bystander proinsulin in neonatal diabetes. J Biol Chem, 2010. 285: p. 685-694.

12. Liu, M., et al., Mutant INS-gene induced diabetes of youth: proinsulin cysteine residues impose dominant-negative inhibition on wild-type proinsulin transport. PLoS One, 2010. 5: p. e13333.

13. Haataja, L., et al., Proinsulin intermolecular interactions during secretory trafficking in pancreatic beta cells. J Biol Chem, 2013. 288(3): p. 1896-906.

14. Wright, J., et al., Dominant protein interactions that influence the pathogenesis of conformational diseases. J Clin Invest, 2013. 123: p. 3124-3134.

15. Cunningham, C.N., et al., Chaperone-driven degradation of a misfolded proinsulin mutant in parallel with restoration of wild type insulin secretion. Diabetes, 2017. 66: p. 741-753.

16. Schuit, F.C., R. Kiekens, and D.G. Pipeleers, Measuring the balance between insulin synthesis and insulin release. Biochem Biophys Res Commun, 1991. 178(3): p. 1182-7.

17. Chang, S.G., et al., Role of disulfide bonds in the structure and activity of human insulin. Mol. Cells, 2003. 16: p. 323-330.

18. Liu, M., J. Ramos-Castañeda, and P. Arvan, Role of the connecting peptide in insulin biosynthesis. J. Biol. Chem., 2003. 278: p. 14798-14805.

19. Haataja, L., et al., Disulfide mispairing during proinsulin folding in the endoplasmic reticulum. Diabetes, 2016. 65(4): p. 1050-60.

20. Herbach, N., et al., Dominant-negative effects of a novel mutated Ins2 allele causes early-onset diabetes and severe beta-cell loss in Munich Ins2C95S mutant mice. Diabetes, 2007. 56: p. 12681276.

21. Hua, Q.X., et al., A protein caught in a kinetic trap: structures and stabilities of insulin disulfide isomers. Biochemistry, 2002. 41: p. 14700-14715.

22. Blundell, T.L., et al., X-ray analysis and the structure of insulin. Recent Prog. Horm. Res., 1971. 27: p. 1-40. 
23. Baker, E.N., et al., The structure of $2 \mathrm{Zn}$ pig insulin crystals at 1.5 A resolution. Phil. Trans. R. Soc. Lond. - Biol. Sci., 1988. 319: p. 369-456.

24. Ortolani, F., et al., Diabetes associated with dominant insulin gene mutations: outcome of 24month, sensor-augmented insulin pump treatment. Acta Diabetol, 2016. 53(3): p. 499-501.

25. Stoy, J., et al., Insulin gene mutations as a cause of permanent neonatal diabetes. Proc Natl Acad Sci U S A, 2007. 104: p. 15040-15044.

26. Piccini, B., et al., Clinical and molecular characterization of a novel INS mutation identified in patients with MODY phenotype. Eur J Med Genet, 2016. 59(11): p. 590-595.

27. Johnson, S.R., et al., A novel INS mutation in a family with maturity-onset diabetes of the young: Variable insulin secretion and putative mechanisms. Pediatric diabetes, 2018. 19(5): p. 905-909.

28. Murray-Rust, J., et al., Structure and evolution of insulins: implications for receptor binding. Bioessays, 1992. 14(5): p. 325-31.

29. Hodish, I., et al., In vivo misfolding of proinsulin below the threshold of frank diabetes. Diabetes, 2011. 60: p. 2092-2101.

30. Orci, L., et al., Conversion of proinsulin to insulin occurs coordinately with acidification of maturing secretory vesicles. J. Cell Biol., 1986. 103: p. 2273-2281.

31. Huang, X.F. and P. Arvan, Formation of the insulin-containing secretory granule core occurs within immature b-granules. J. Biol. Chem., 1994. 269: p. 20838-20844.

32. Arunagiri, A., et al., Proinsulin misfolding is an early event in the progression to type 2 diabetes. eLife, 2019. 8.

33. Zhu, S., et al., Monitoring C-Peptide Storage and Secretion in Islet beta-Cells In Vitro and In Vivo. Diabetes, 2016. 65(3): p. 699-709.

34. Sun, J., et al., Role of proinsulin self-association in Mutant INS gene-induced Diabetes of Youth. Diabetes, 2020. 69(5): p. 954-964.

35. Rege, N.K., et al., Evolution of insulin at the edge of foldability and its medical implications. Proc Natl Acad Sci U S A, 2020. 117: p. 29618-29628.

36. Gregoret, L.M. and R.T. Sauer, Tolerance of a protein helix to multiple alanine and valine substitutions. Folding \& design, 1998. 3(2): p. 119-26.

37. Markert, M.L., C. Norby-Slycord, and F.E. Ward, A high proportion of ADA point mutations associated with a specific alanine-to-valine substitution. American journal of human genetics, 1989. 45(3): p. 354-61.

38. Austin, A.L.F., et al., The KINGS Ins2+/G32S mouse: a novel model of beta cell endoplasmic reticulum stress and human diabetes. Diabetes, 2020.

39. Weiss, M.A., The structure and function of insulin: decoding the TR transition. Vitamins and hormones, 2009. 80: p. 33-49.

40. Hua, Q.X., et al., A conserved histidine in insulin is required for the foldability of human proinsulin: structure and function of an ALAB5 analog. J Biol Chem, 2006. 281(34): p. 24889-99.

41. Sohma, Y., et al., Contribution of residue B5 to the folding and function of insulin and IGF-I: constraints and fine-tuning in the evolution of a protein family. J Biol Chem, 2010. 285: p. 50405055.

42. Weiss, M.A., et al., NMR and photo-CIDNP studies of human proinsulin and prohormone processing intermediates with application to endopeptidase recognition. Biochemistry, 1990. 29: p. 8389-8401.

43. Hua, Q.-X., W. Jia, and M.A. Weiss, Conformational dynamics of insulin. Frontiers in endocrinology, 2011. 2: p. 48.

44. van Lierop, B., et al., Insulin in motion: The A6-A11 disulfide bond allosterically modulates structural transitions required for insulin activity. Scientific reports, 2017. 7(1): p. 17239.

45. Nakagawa, S.H., et al., Chiral mutagenesis of insulin. Foldability and function are inversely regulated by a stereospecific switch in the B chain. Biochemistry, 2005. 44(13): p. 4984-99. 
46. Avital-Shmilovici, M., et al., Deciphering a molecular mechanism of neonatal diabetes mellitus by the chemical synthesis of a protein diastereomer, [D-AlaB8]human proinsulin. The Journal of biological chemistry, 2014. 289(34): p. 23683-92.

47. Hua, Q.X., et al., The folding nucleus of the insulin superfamily: a flexible peptide model foreshadows the native state. J Biol Chem, 2006. 281: p. 28131-28142.

48. Liu, M., et al., Crystal structure of a "nonfoldable" insulin: impaired folding efficiency despite native activity. J Biol Chem, 2009. 284: p. 35259-35272.

49. Jang, I., et al., PDIA1/P4HB is required for efficient proinsulin maturation and ss cell health in response to diet induced obesity. Elife, 2019. 8. 


\section{Figure Legends}

Figure 1. Position of missense MIDY mutants studied in this manuscript, shown relative to the peptide sequence of human insulin. A) Numbering of residues of the insulin B-chain, and insulin A-chain (referring to peptide sequence as residues B1 to B30, and A1 to A21, respectively) is shown near the top of the Figure (the C-peptide is not shown). The $\mathrm{X}$-axis indicates the primary structure of mature human insulin (single-letter code) organized as a map of the degree of sequence variability at each position, from [28] - negative values indicate higher conservation with increasingly positive values showing greater levels of variability. Cys residues are shown in gold and native disulfide bonds indicated as solid gold lines. Mutations altering endogenous human proinsulin residues, engineered in this study, are shown as circles in single-letter code. The double-mutant C(A6)S,C(A11)S is referred to in this manuscript as 'loseA6/A11', and a dashed gold line indicates what would normally be a native disulfide bond that cannot be made in this double-mutant. Replacement of $\mathrm{Val}(\mathrm{B} 18)$ with Ala is shown in a unique color (purple) designating its unique behavior described herein. G(B8)V, Y(B26)C, and L(A16)P are each shown in red font within white circles, signifying resistance to secretion rescue in the lose-A6/A11 background. The remaining studied mutations are shown as yellow font in black circles, signify MIDY mutants that exhibit significant secretion rescue within the lose-A6/A11 background. A dibasic cleavage site separates the Cpeptide from the A-chain, the second residue of which is the site of the R(Cpep+2)C MIDY mutation, which has also been described as R(89)C. B) Two-chain structure of insulin with B-chain (top; dark gray) and A-chain (bottom; light gray). Sites of mutation within the insulin moiety of proinsulin considered in this study are highlighted in red. Disulfide bridges are shown as black lines with sulfur atoms as filled gold circles. C) Crystallographic T-state protomer (Protein Databank entry 4INS, 2-Zn molecule-1) with B-chain in blue, A-chain in red, sulfur atoms engaged in three cystines (B7-A7, B19-A20 and A6-A11) shown in gold, and sites of mutation within the insulin moiety of proinsulin considered in this study denoted (the $\mathrm{C}_{\mathrm{a}}$ carbon of $\mathrm{Gly}^{\mathrm{B} 8}$ is shown as a red ball).

Figure 2. Co-expression of human mutant proinsulin with mouse wild-type proinsulin demonstrates dominant-negative inhibition of proinsulin export. 293T cells were co-transfected to express mouse WT proinsulin and myc-tagged human WT or MIDY mutant proinsulin at a plasmid ratio of $1: 2$, respectively [10]. Beginning at $6 \mathrm{~h}$ post-transfection, cell culture media was collected for one day, and the cells were then lysed. Cellular content and secretion of proinsulin was proportionately loaded and resolved by SDSPAGE. A) Cell and media content of myc-tagged proinsulins by immunoblotting with anti-myc antibody; tagged-WT proinsulin was secreted (green arrow). B) Cell and media content of co-expressed untagged mouse WT proinsulin by immunoblotting with rodent-specific anti- proinsulin mAb; untagged-WT 
proinsulin was secreted (green arrow). C) Secretion of WT or MIDY mutant human proinsulins were quantified from three independent replicate experiments conducted as in panel A.

Figure 3. Mutant human proinsulin export in $\beta$-cells. Min6 $\beta$-cells were transfected with plasmids encoding myc-tagged human WT or MIDY mutant proinsulins, as indicated. At $48 \mathrm{~h}$ post-transfection, cell culture media was collected overnight, and the cells were lysed. Cell lysates and secretion media were proportionately loaded and resolved by SDS-PAGE and electrotransfer to nitrocellulose. A) Cell and media content of myc-tagged proinsulins by immunoblotting with anti-myc antibody, demonstrating abundant secretion of WT human proinsulin (green arrow). B) Confirming that myc-tagged WT proinsulin is competent in the biosynthesis of authentic (human) insulin, secretion was measured by human-specific insulin ELISA; endogenous rodent insulin (from nontransfected cells, 'nt') cannot be detected in the assay (mean \pm s.d. shown from 3 independent experiments, ${ }^{*} p<0.05$ ). C) Secretion of myc-tagged human WT and MIDY mutant proinsulins like that shown in panel A were quantified by scanning densitometry $(\mathrm{n}=5$ independent experiments); with $p$-values on the figure.

Figure 4. Oxidation and secretion of newly-synthesized mutant proinsulin. INS832/13 $\beta$-cells transfected to express myc-tagged human WT or MIDY mutant proinsulins were pulse-labeled with ${ }^{35} \mathrm{~S}$-labeled amino acids for 30 min and either lysed immediately (zero chase time, panels A, B) or chased in complete media for $3 \mathrm{~h}$ (panels C, D). Chase media were collected and the cells were lysed (see Methods). A) Cell lysates were immunoprecipitated with anti-Myc antibodies and analyzed by nonreducing (upper panel) or reducing Tris-tricine-urea-SDS-PAGE (lower panel) and phosphorimaging. A dashed light-blue line shows the position of the oxidized proinsulin monomer; all lanes come from the same gel image. B) At the zero chase time, the fastest-migrating form of oxidized proinsulin, as a fraction of total proinsulin, was quantified (mean \pm s.d. from at least 3 independent experiments). C) After $3 \mathrm{~h}$ chase, cell lysates (C) and media (M) were immunoprecipitated with anti-Myc-antibodies and analyzed by reducing SDS-PAGE and phosphorimaging. D) Experiments like that shown in panel $\mathrm{C}$ were performed in at least 3 independent experiments, and secretion quantified (mean \pm s.d.); with $p$-values shown on the figure.

Figure 5. Disulfide-linked complexes of MIDY proinsulins tend to be rescued in the lose-A6/A11 background. A) Min6 $\beta$-cells were transiently transfected to express myc-tagged human WT or MIDY mutant proinsulins, as indicated. At $48 \mathrm{~h}$ post-transfection, the cells were lysed and analyzed by nonreducing or reducing SDS-PAGE (NuPAGE), electrotransfer, and immunoblotting with anti-humanproinsulin $\mathrm{mAb}$ (directed against a sequence spanning the human B-chain/C-peptide junction). From nonreducing gels, proinsulin was detected either as monomer (band labeled 'Proins') or in a ladder of 
disulfide-linked dimers, trimers and higher-molecular weight disulfide-linked complexes (as indicated). B) Min6 $\beta$-cells were transiently transfected to express myc-tagged lose-A6/A11 proinsulins bearing WT or MIDY mutations, and analyzed exactly as in panel A. Note that the antibody does not detect any endogenous proinsulin of nontransfected mouse $\beta$-cells under either nonreducing or reducing conditions (lane 9, "nt").

Figure 6. Some mutant proinsulins in the lose-A6/A11 background are secreted. Min6 $\beta$-cells were transfected to express myc-tagged human lose-A6/A11 WT proinsulin, or that bearing MIDY mutants as indicated. At $48 \mathrm{~h}$ post-transfection, cell culture media was collected overnight, and the cells were lysed. Cell lysates and media were proportionately loaded and resolved by SDS-PAGE. A) Cell and media content of myc-tagged proinsulins resolved under reducing conditions, analyzed by immunoblotting with anti-Myc antibody; WT proinsulin is secreted (green arrow). B) Secretion of lose-A6/A11 constructs like those in panel A were quantified in comparison to that of the same MIDY mutants in the WT proinsulin background, from Fig 3C. Secretion from at least three independent experiments is shown; $p$-values (on the figure) were analyzed for the lose-A6/A11 background (hatched bars) compared to the proinsulin background (solid bars). C+D) INS832/13 cells were transfected to express myc-tagged human loseA6/A11 proinsulin or that bearing MIDY mutants as indicated. At $48 \mathrm{~h}$ post-transfection, the cells were pulse-labeled with ${ }^{35}$ S-labeled amino acids for $30 \mathrm{~min}$. C) Samples were lysed immediately, processed as in Fig. 4A, and analyzed by nonreducing (upper panel) or reducing Tris-tricine-urea-SDS-PAGE (lower panel) and phosphorimaging. D) Samples were chased for $90 \mathrm{~min}$; cell lysates (C) and media (M) were immunoprecipitated with anti-Myc antibodies and processed as in Fig. 4C (reducing SDS-PAGE and phosphorimaging). E) Secretion of the MIDY mutants in the WT proinsulin background (solid bars) or lose-A6/A11 background (hatched bars) was quantified (mean \pm s.d. from at least 3 independent experiments). In each experiment, for the insulin chain sequence not bearing a MIDY mutation, secretion was set to $100 \%$.

Figure 7. Intracellular distribution of MIDY mutant proinsulins in live $\beta$-cells. A) Live cell imaging of INS832/13 cells transfected to transiently express fluorescent WT or MIDY proinsulins (and their derived fluorescent protein products) bearing superfolder-GFP embedded within the C-peptide. Upper panels show each construct contained within the hPro-CpepSfGFP background. Lower panels show the same WT and MIDY mutants in which the hPro-CpepSfGFP bears the lose-A6/A11 substitutions. White scale bar = $10 \mu \mathrm{m}$. (Additional "volume views" using 3D-tilt images are shown in Supplemental Fig. S5.) B) AntiGFP immunoblotting of cell lysates from INS832/13 cells transiently transfected as in panel A, and resolved by reducing SDS-PAGE. Upper panels show the dark full-length hPro-CpepGFP band for each 
construct. The construct bearing the WT insulin chains also demonstrates an endoproteolytic processing intermediate ('Inter') and the fully-mature CpepSfGFP (green arrow). Lower panels show the same constructs in the lose-A6/A11 background, demonstrating more obvious endoproteolytic processing for $\mathrm{H}(\mathrm{B} 5) \mathrm{D}, \mathrm{R}(\mathrm{Cpep}+2) \mathrm{C}$, and $\mathrm{E}(\mathrm{A} 4) \mathrm{K}$ (green arrows). A representative experiment (of three) is shown. C) 293 T cells were either untransfected ('U') or transiently transfected to express hPro-CpepSfGFP without (WT) or with the G(B8)V MIDY mutation. At $48 \mathrm{~h}$ post-transfection, the cells were pulse-labeled with ${ }^{35} \mathrm{~S}$-labeled amino acids and either lysed immediately, or chased for $90 \mathrm{~min}$ as indicated. Cell lysates and media were immunoprecipitated with anti-GFP antibodies and analyzed by C) nonreducing, or D) reducing SDS-PAGE and phosphorimaging. hPro-G(B8)V-CpepSfGFP was retained intracellularly and did not appear in the medium. E) Recovery of newly-synthesized hPro-CpepGFP and hPro-G(B8)V-CpepSfGFP from $n=3$ experiments (mean + s.d.).

Figure 8. Co-expression of myc-tagged lose-A6/A11-MIDY proinsulin with mouse WT proinsulin does not efficiently block untagged WT proinsulin export. 293T cells were co-transfected to express untagged mouse WT proinsulin-2 and myc-tagged human WT or MIDY mutant in the lose-A6/A11 background. Transfection and sample processing was exactly as in Fig. 2. A) Cell and media content of myc-tagged lose-A6/A11 proinsulins, immunoblotted with anti-Myc (as in Fig. 2A); tagged-WT proinsulin was secreted (green arrow). B) Cell and media content of co-expressed untagged mouse WT proinsulin, immunoblotted with anti-rodent proinsulin (as in Fig. 2B); untagged-WT proinsulin was secreted (green arrow). C) Secretion of WT or MIDY mutant human proinsulins in the lose-A6/A11 background, quantified from three independent replicate experiments conducted similarly to that described in panel A. Mean + s.d. from $n=3$ independent experiments. Secretion of $H(B 5) D, R(C p e p+2)$, and $E(A 4) K$ was significantly increased compared to other MIDY mutants $\mathrm{G}(\mathrm{B} 8) \mathrm{V}, \mathrm{Y}(\mathrm{B} 26) \mathrm{C}$, and L(A16)P ( $p$-values shown on Figure). 


\begin{tabular}{|c|c|c|c|c|}
\hline \multicolumn{5}{|l|}{ Key Resources Table } \\
\hline $\begin{array}{c}\text { Reagent type (species) } \\
\text { or resource }\end{array}$ & Designation & Source or reference & Identifiers & $\begin{array}{l}\text { Additional } \\
\text { info }\end{array}$ \\
\hline cell line (rat) & INS-1 832/13 (rat beta cell line) & $\begin{array}{l}\text { Hohmeier et al. Diabetes } 2000 \\
49: 424-430 .\end{array}$ & $\begin{array}{l}\text { Duke } \\
\text { University }\end{array}$ & $\begin{array}{l}\text { 2011: Dr. C. } \\
\text { Newgard }\end{array}$ \\
\hline cell line (mouse) & Min6 (mouse beta cell line) & $\begin{array}{l}\text { Khoo et al., Endocrinology } \\
2011 \text { 152: } 2599-2608 .\end{array}$ & $\begin{array}{l}\text { University of } \\
\text { Pennsylvania }\end{array}$ & $\begin{array}{l}\text { 2020: Dr. D. } \\
\text { Stoffers }\end{array}$ \\
\hline cell line (human) & $\begin{array}{l}\text { HEK293T (human embryonic } \\
\text { kidney cell line) }\end{array}$ & https://www.atcc.org & CRL-3216 & ATCC \\
\hline antibody & $\begin{array}{l}\text { mouse anti-human proinsulin } \\
\mathrm{C} / \mathrm{A} \text {-junction, or } \mathrm{B} / \mathrm{C} \text {-junction }\end{array}$ & \begin{tabular}{|l|} 
Abmart, Arunagiri et al., eLife \\
2019 doi: $0.7554 / e L i f e .44532$. \\
\end{tabular} & & $(1: 1000)$ \\
\hline antibody & mouse anti-rat proinsulin, $\mathrm{CCl}-17$ & Alpco & $\mathrm{CCl}-17$ & $(1: 1000)$ \\
\hline antibody & guinea pig anti-insulin & Covance & & $(1: 500)$ \\
\hline antibody & anti-Myc (rat polyclonal) & Immunology Consultants Labs & RMYC-45A & $(1: 500)$ \\
\hline antibody & anti-GFP rabbit (rabbit polyclonal) & Immunology Consultants Labs & $\begin{array}{l}\text { RGFP-45ALY- } \\
\text { Z }\end{array}$ & $(1: 1000)$ \\
\hline antibody & Rabbit anti-cyclophilin B & Thermo Fisher & PA1-027A & $(1: 1000)$ \\
\hline antibody & Alexa 488- secondary & Invitrogen & & $(1: 500)$ \\
\hline antibody & HRP-g.p., rabbit or mouse $2^{\circ}$ & Jackson ImmunoResearch & & $(1: 5000)$ \\
\hline recombinant DNA reagent & pTARGET (vector) & Promega & A1410 & \\
\hline recombinant DNA reagent & Myc-wild-type proinsulin (plasmid) & Liu et al PLoS One 2010 & & hum. proins. \\
\hline recombinant DNA reagent & Myc-lose-B19/A20 (plasmid) & Haataja et al Diabetes 2016 & & hum. proins. \\
\hline recombinant DNA reagent & hPro-CpepSfGFP (plasmid) & Haataja et al JBC 2013 & & hum. proins. \\
\hline recombinant DNA reagent & BiP-luciferase (plasmid) & Tirasophon et al 1998 & & \\
\hline recombinant DNA reagent & Renilla luciferase (plasmid) & Tirasophon et al 1998 & & \\
\hline commercial assay or kit & $\begin{array}{l}\text { QuikChange II Site-Directed } \\
\text { Mutagenesis Kit }\end{array}$ & Agilent Technologies & Agilent:200524 & \\
\hline commercial assay or kit & Dual Luciferase Reporter Assay & Promega & \multirow{6}{*}{\begin{tabular}{|l|} 
A1910 \\
$80-I N S H U-$ \\
CH01 \\
\\
E3876 \\
NEG072007M \\
C \\
50618 \\
\end{tabular}} & \\
\hline commercial assay or kit & human insulin ELISA STELLUX & ALPCO & & \\
\hline commercial assay or kit & $\begin{array}{l}\text { Enhanced chemiluminescence } \\
\text { Immobilon or Clarity }\end{array}$ & Millipore or BioRad & & \\
\hline chemical compound, drug & $\mathrm{N}$-Ethylmaleimide (NEM) & SIGMA & & \\
\hline chemical compound, drug & Trans ${ }^{35} \mathrm{~S}$ Label & Perkin-Elmer & & \\
\hline chemical compound, drug & ProSieve 50 Gel Solution & Lonza & & \\
\hline chemical compound, drug & $\begin{array}{l}\text { protease inhibitor cocktail } \\
\text { complete Mini }\end{array}$ & Roche & \multirow[t]{8}{*}{11836153001} & \\
\hline chemical compound, drug & protein $A$ agarose & Invitrogen & & \\
\hline chemical compound, drug & dithiothreitol, Pansorbin, urea & Sigma-Aldrich or ThermoFisher & & \\
\hline Reagent & Lipofectamine 2000 & ThermoFisher Scientific & & \\
\hline Reagent & tissue culture reagents & ThermoFisher Scientific & & \\
\hline Reagent & $\begin{array}{l}\text { Met/Cys-deficient RPMI or DMEM } \\
\text { medium }\end{array}$ & Sigma & & \\
\hline Reagent & 4-12\% Bis-Tris NuPage gels & Invitrogen & & \\
\hline Cell Culture Imaging & Nunc LabTek-II Chambers & ThermoFisher Scientific & & \\
\hline software, algorithm & Graphpad PRISM 8.0 & GraphPad & & \\
\hline
\end{tabular}


A

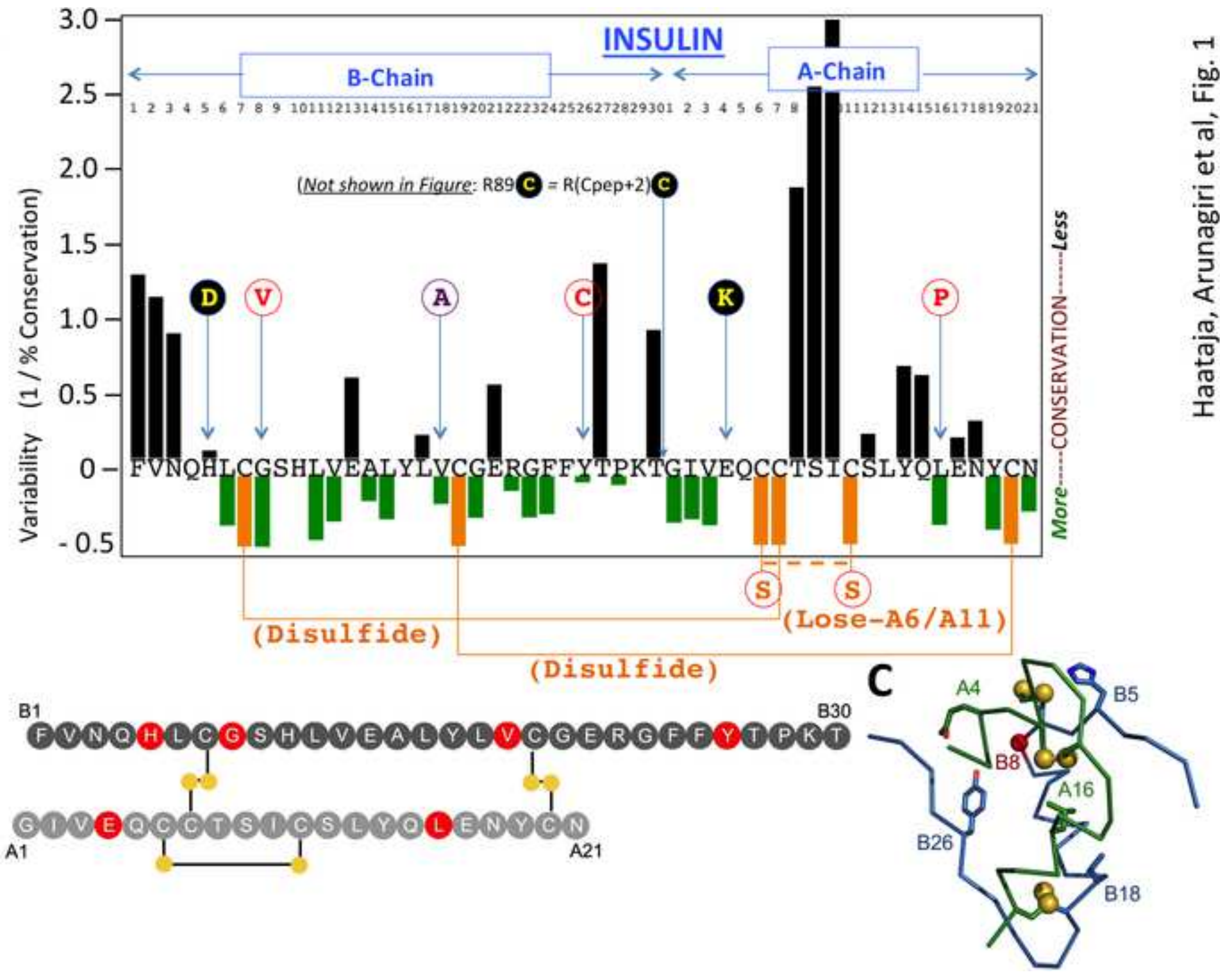

B

B1 I A1 1 
A untagged mouse WT-proinsulin + hPro-CpepMyc: s s

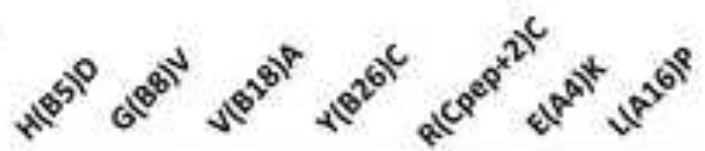
Myc-proinsulin (Cells)

Myc-proinsulin (Media)

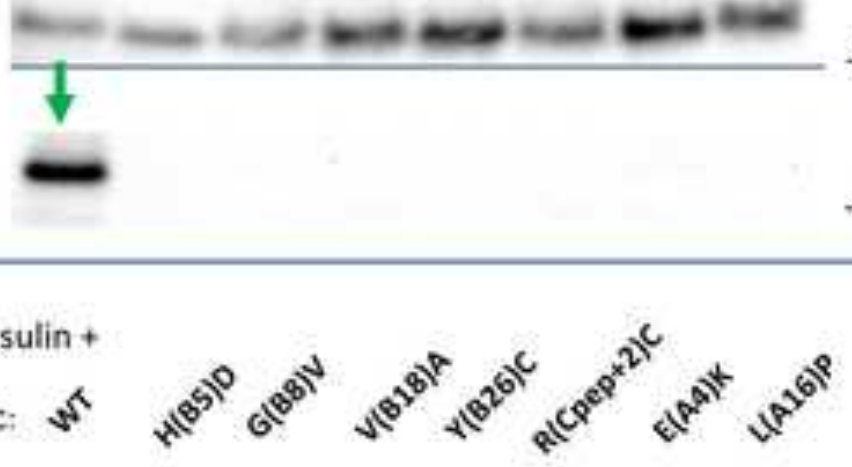

B

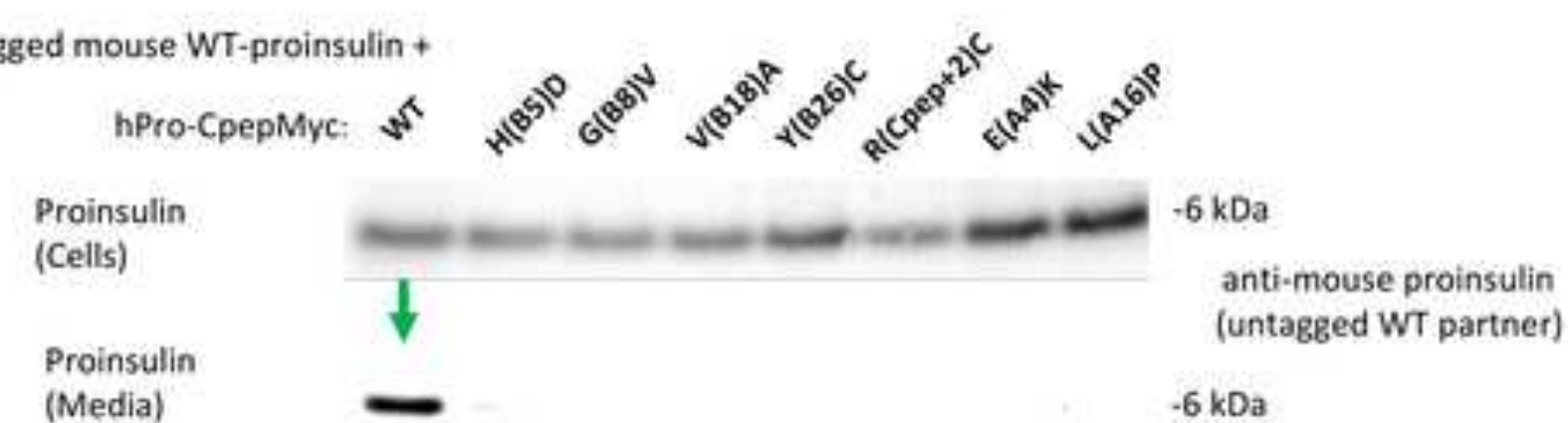

C

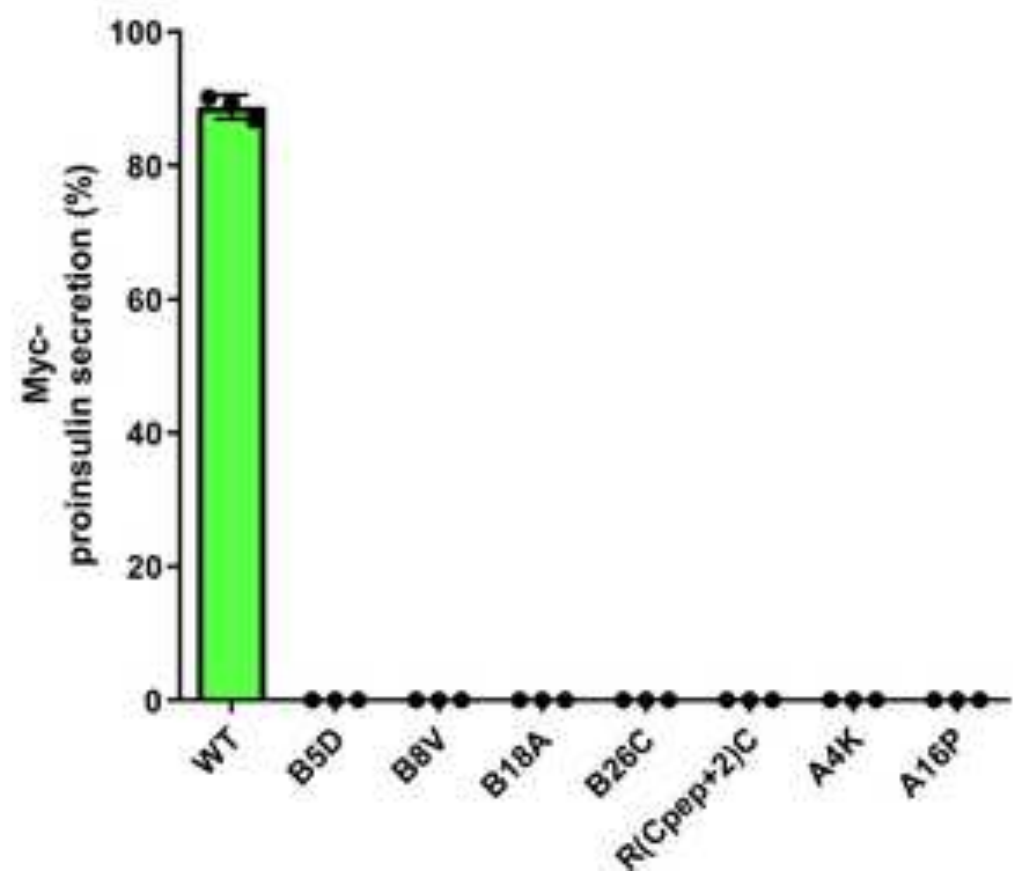

$-6 \mathrm{kDa}$ anti-Myc

(tagged WT or

mutant partner)

$-6 \mathrm{kDa}$
Media)

Haataja, Arunagiri et al., Fig. 2 
A

Myc-Proinsulin:

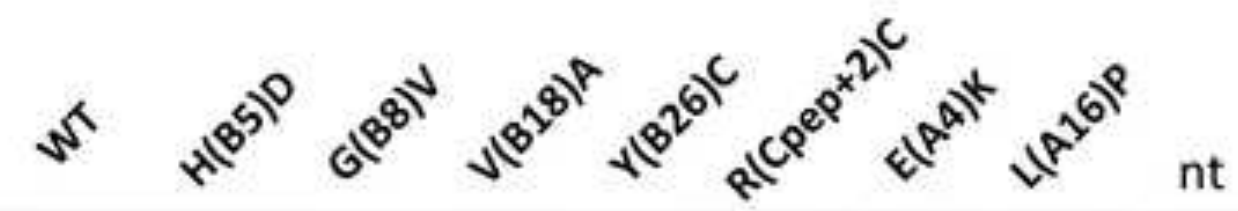

Myc-proinsulin (Cells)

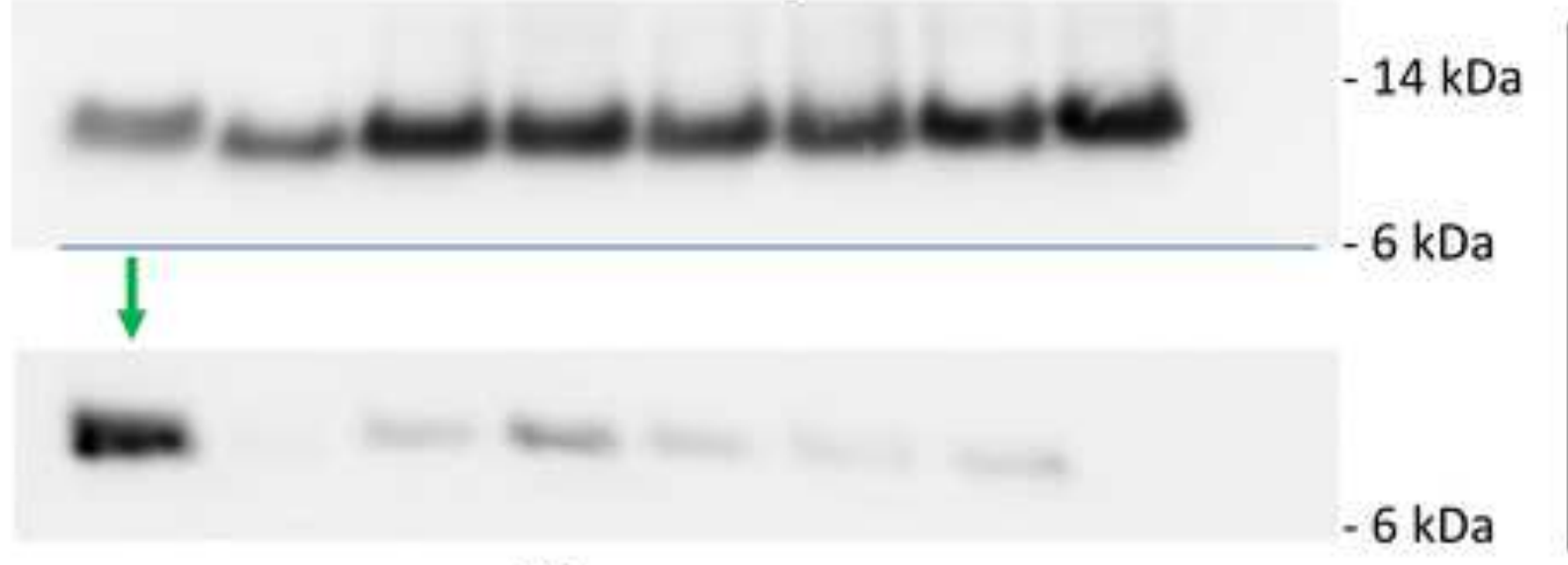

anti-Myc

Myc-proinsulin (Media)

B
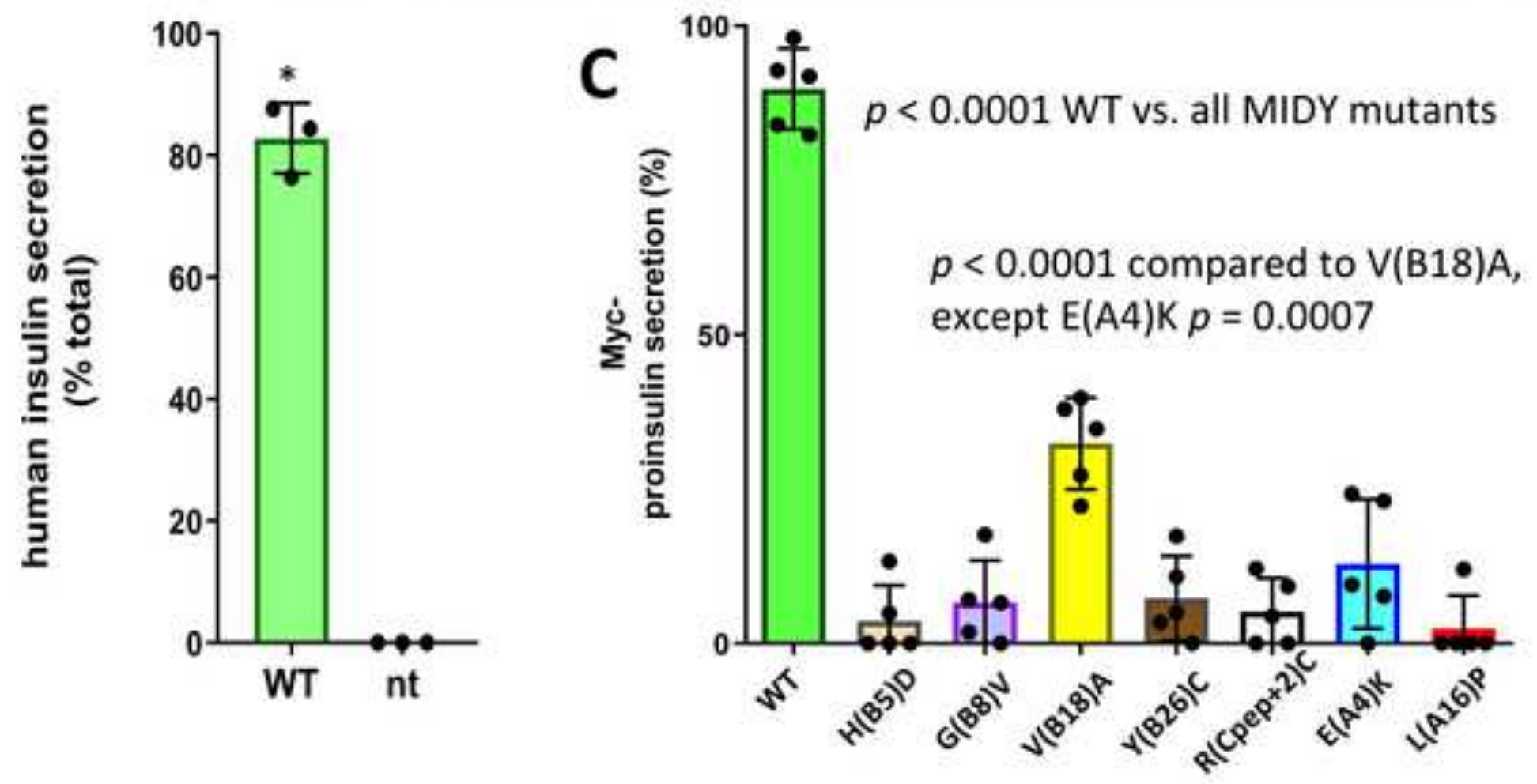

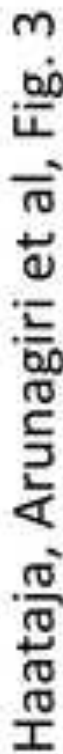

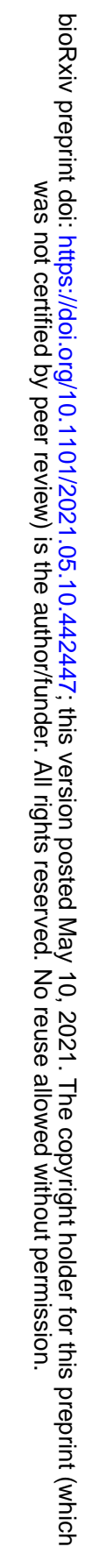




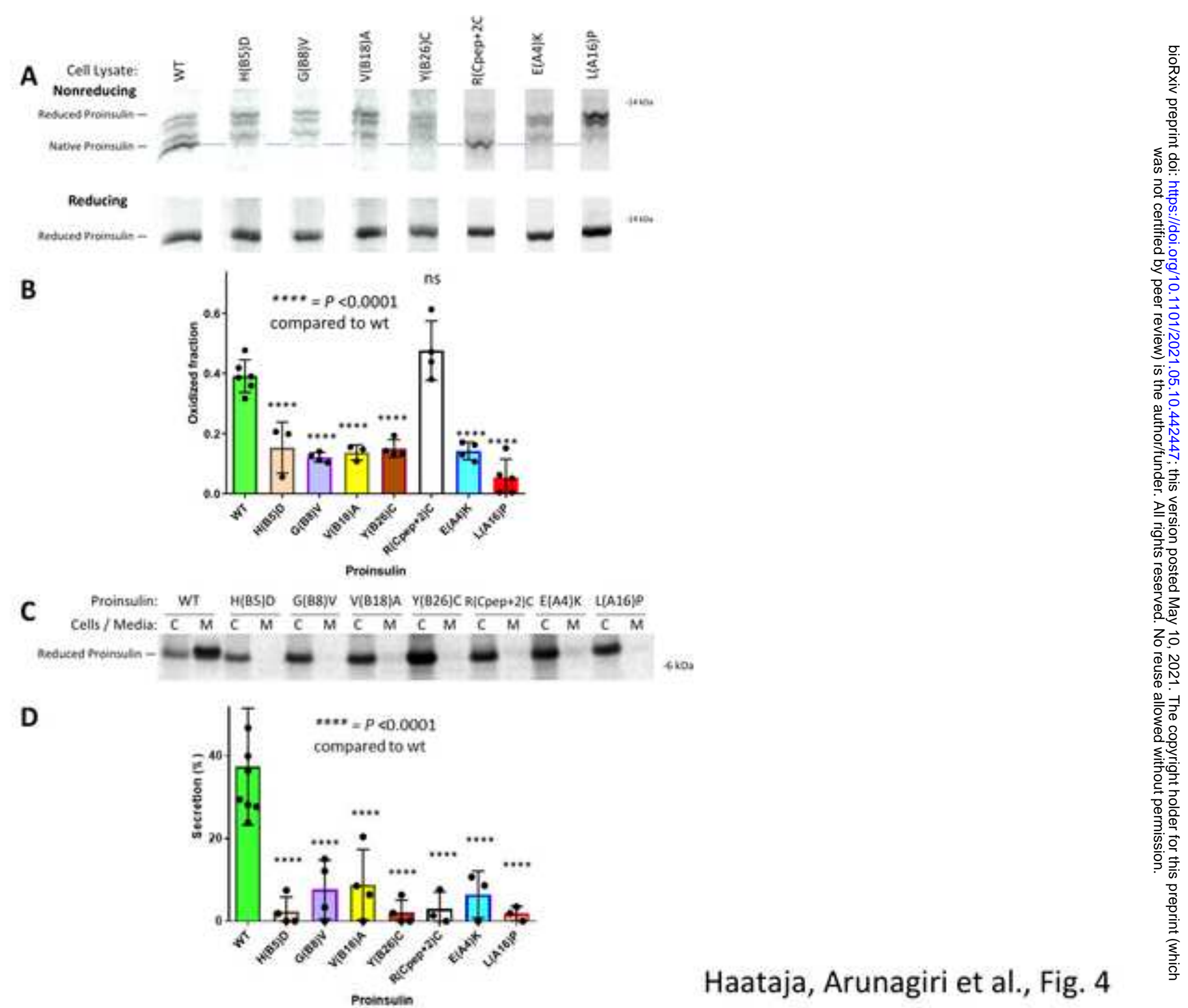




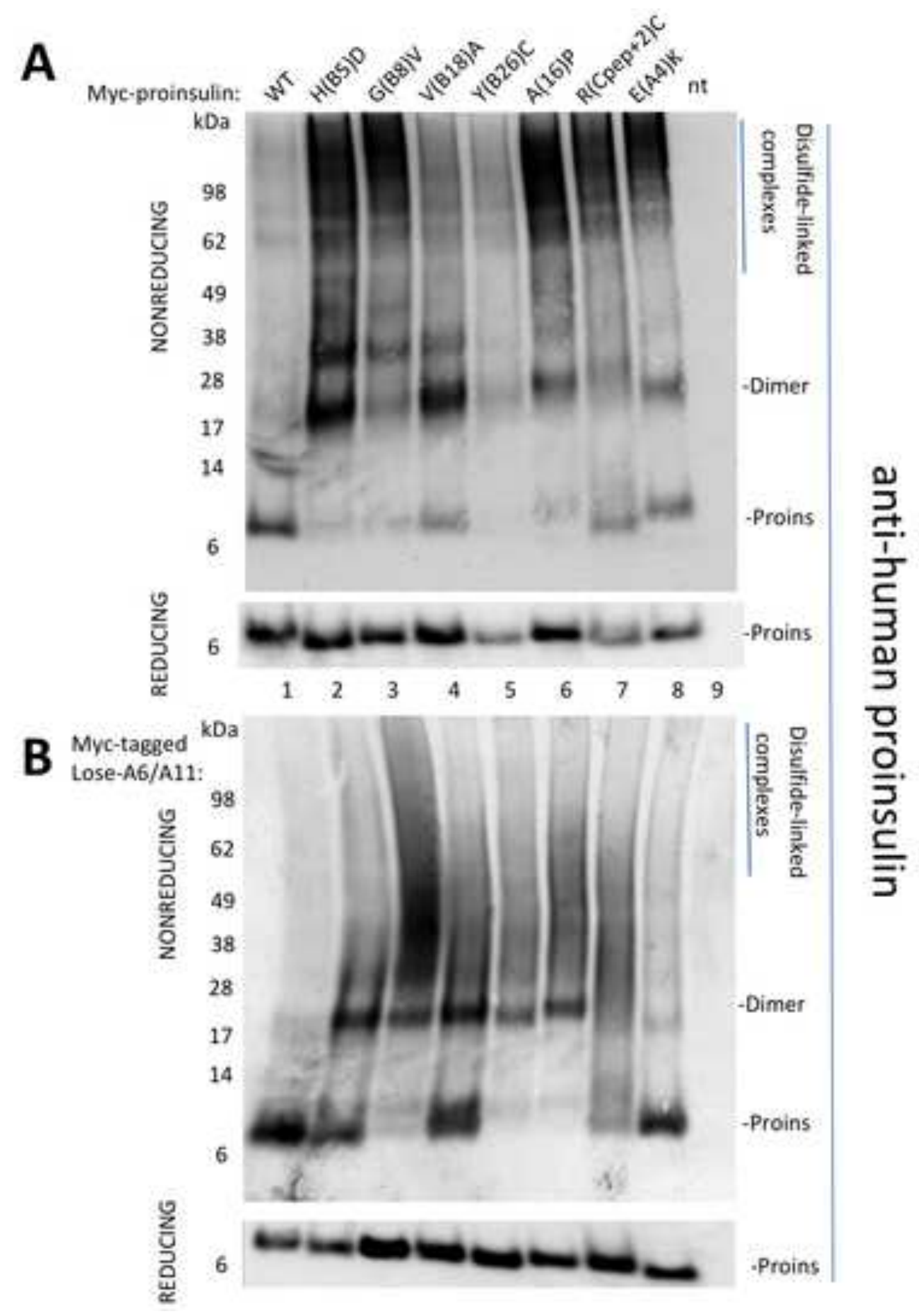

Haataja, Arunagiri et al., Fig. 5 


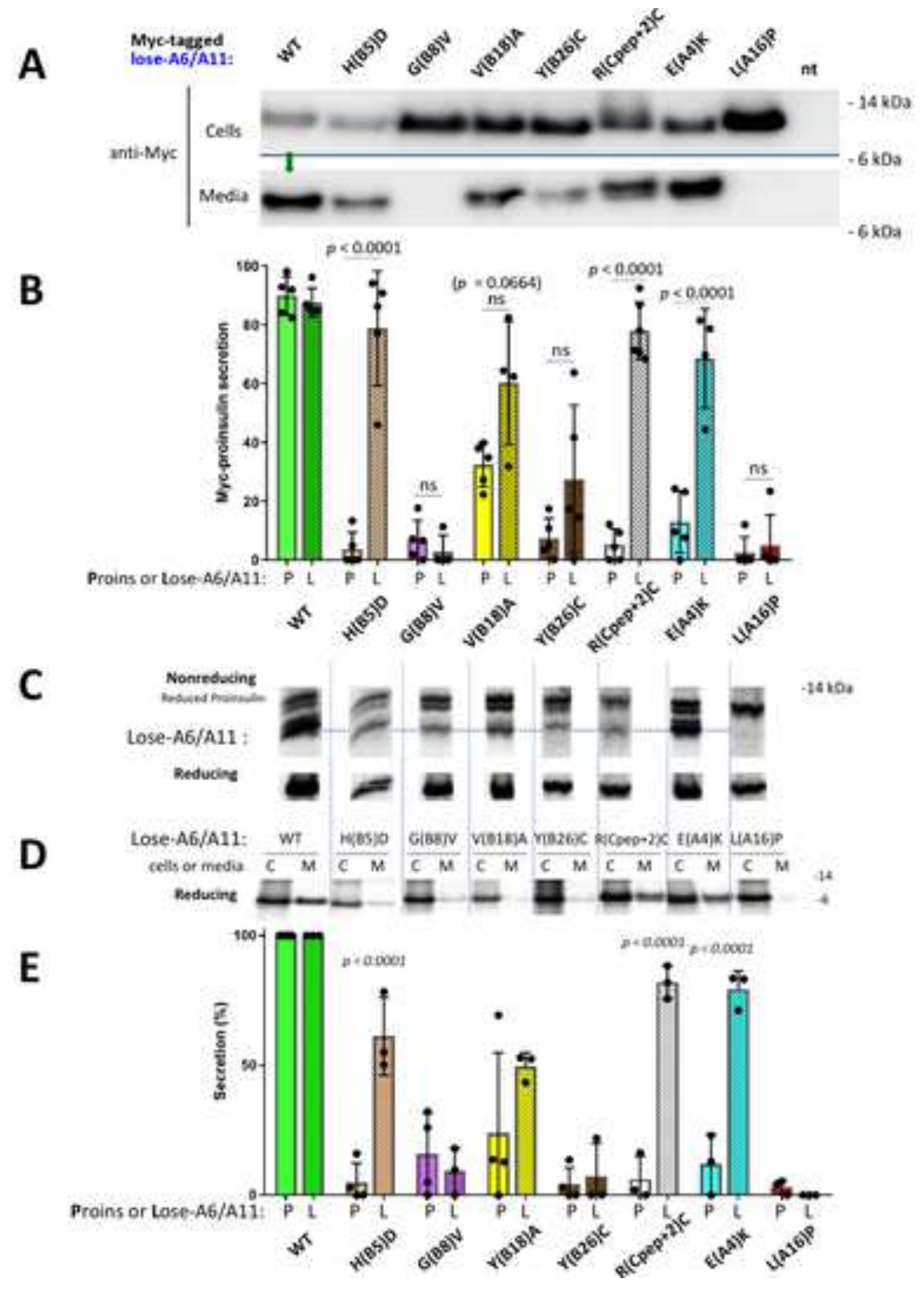

6

فำ

-

ते

๘

등

돌

4

营

苋

I

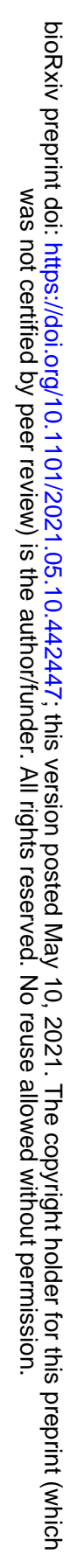


A
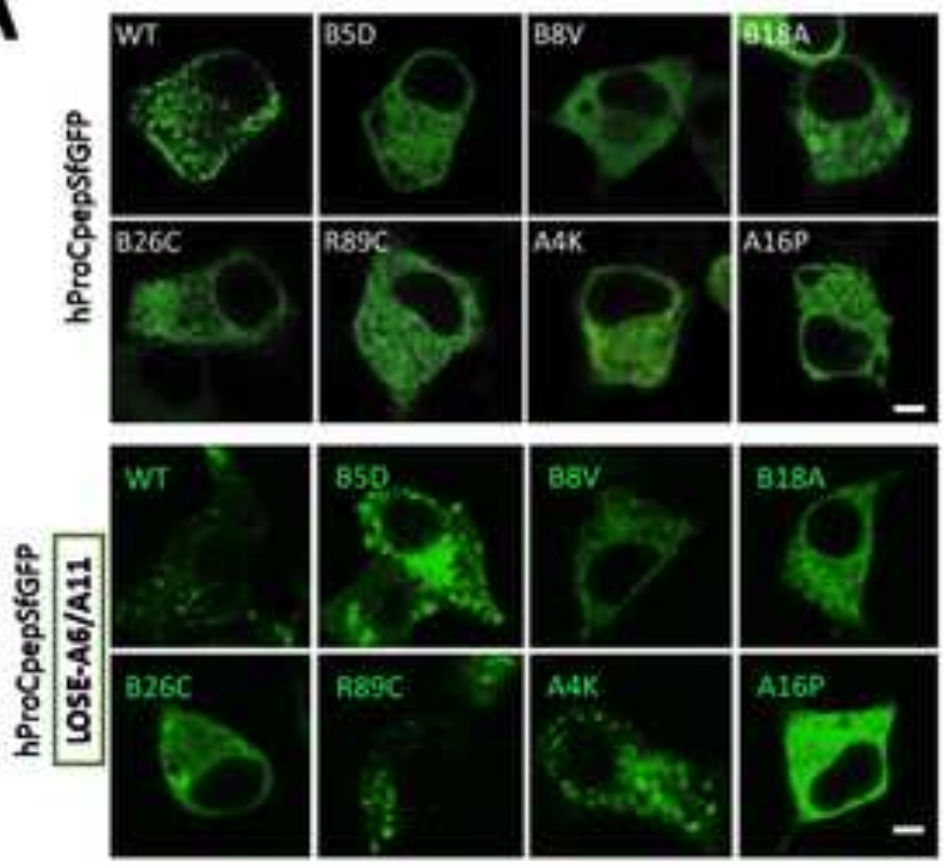

C

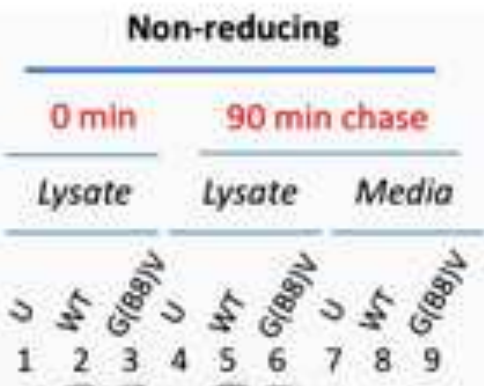

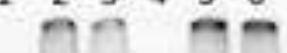

D

\begin{tabular}{|c|c|c|}
\hline $0 \mathrm{~min}$ & $90 \mathrm{mi}$ & chase \\
\hline Lysate & Lysate & Media \\
\hline
\end{tabular}

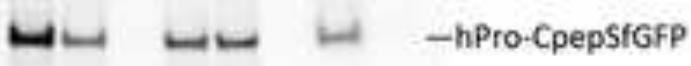

B
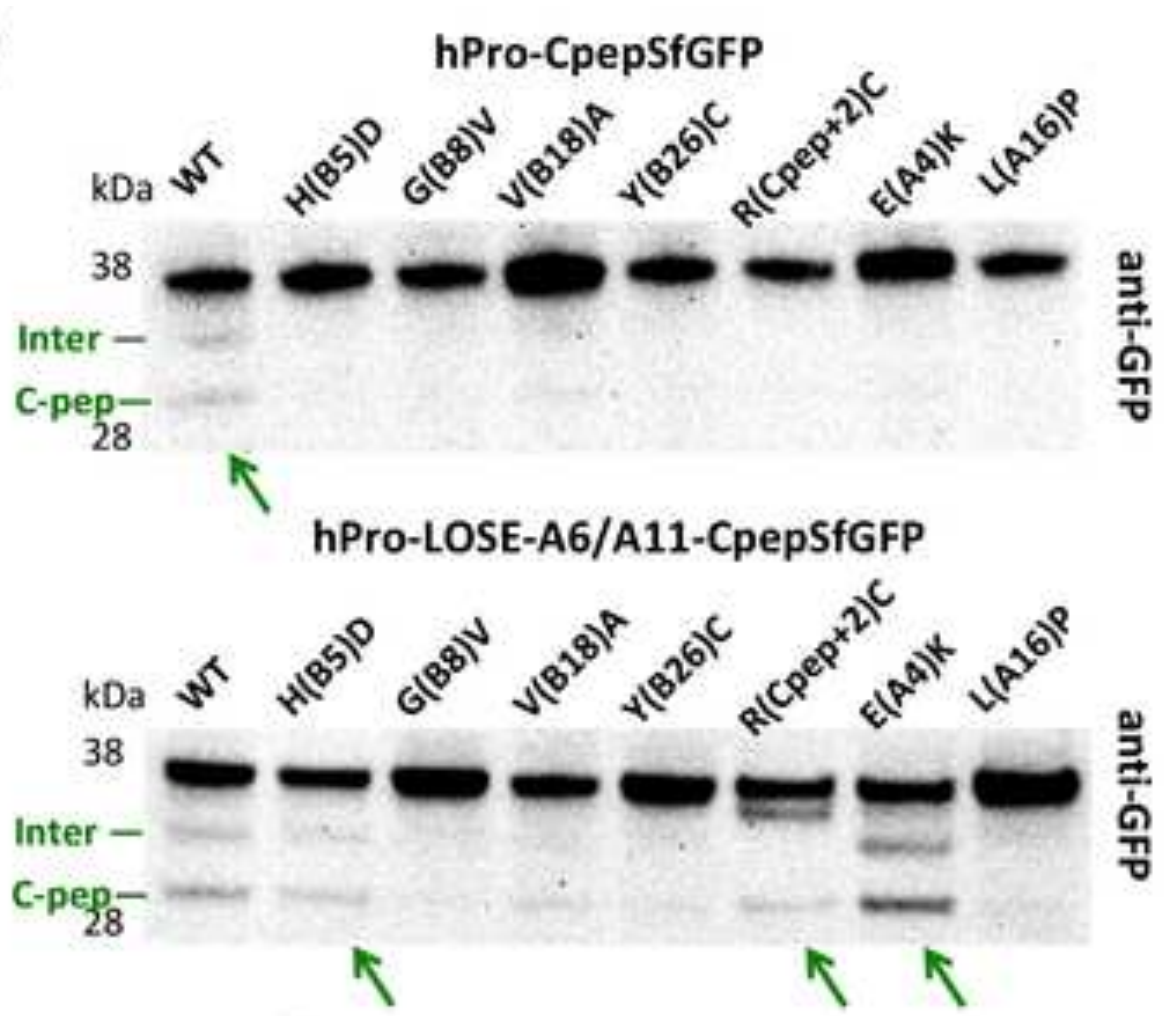

E

hPro-CpepSfGFP

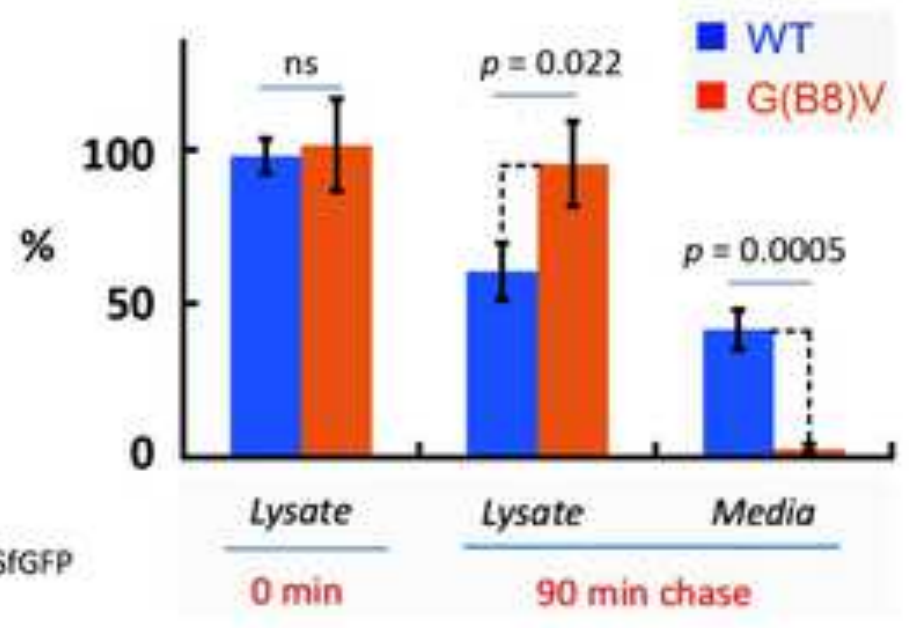

N

응

ले

吅

든

(ొ)

논

.

营

胥

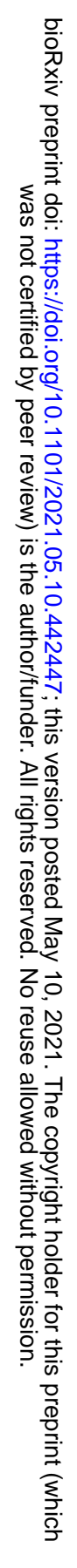


A untagged mouse wild type proinsulin +

Myc-tagged lose-A6/A11:

\section{Cells}

Media
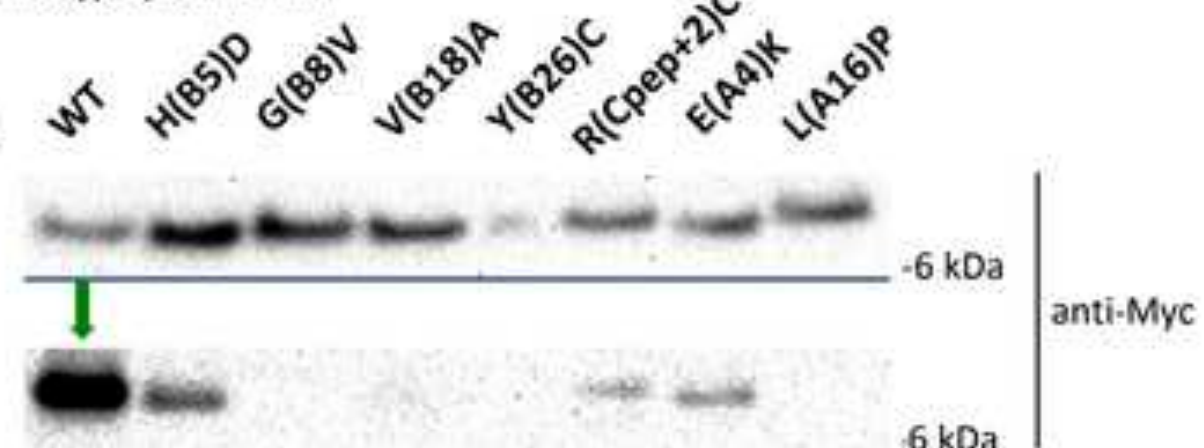

B

untagged mouse wild type proinsulin +

Myc-tagged lose-A6/A11:
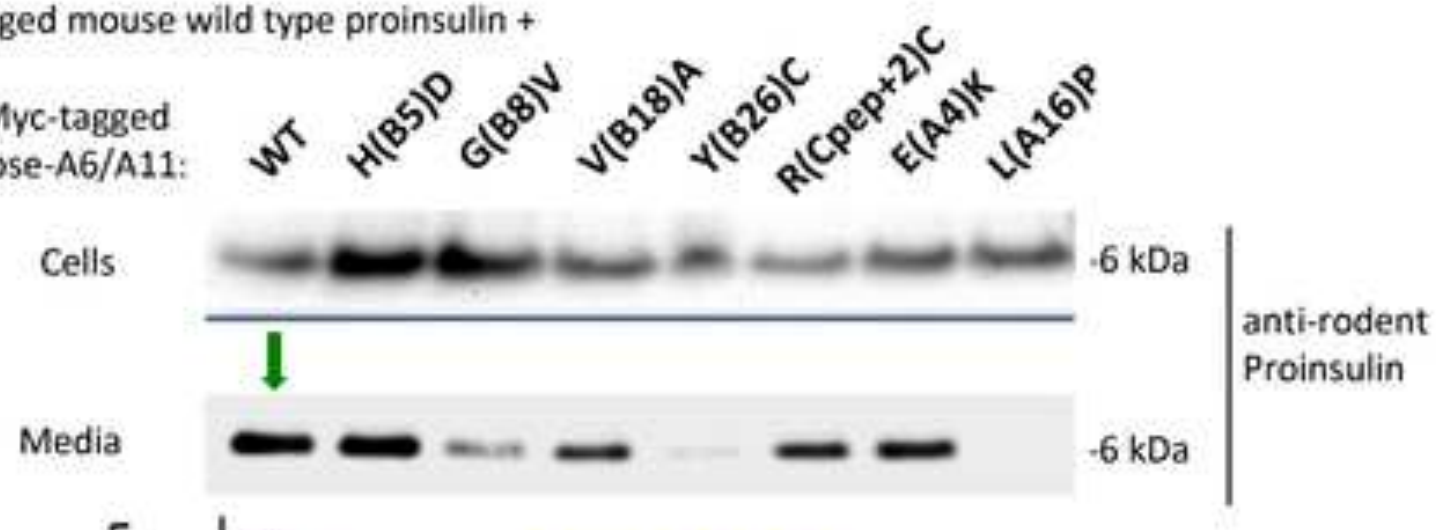

C

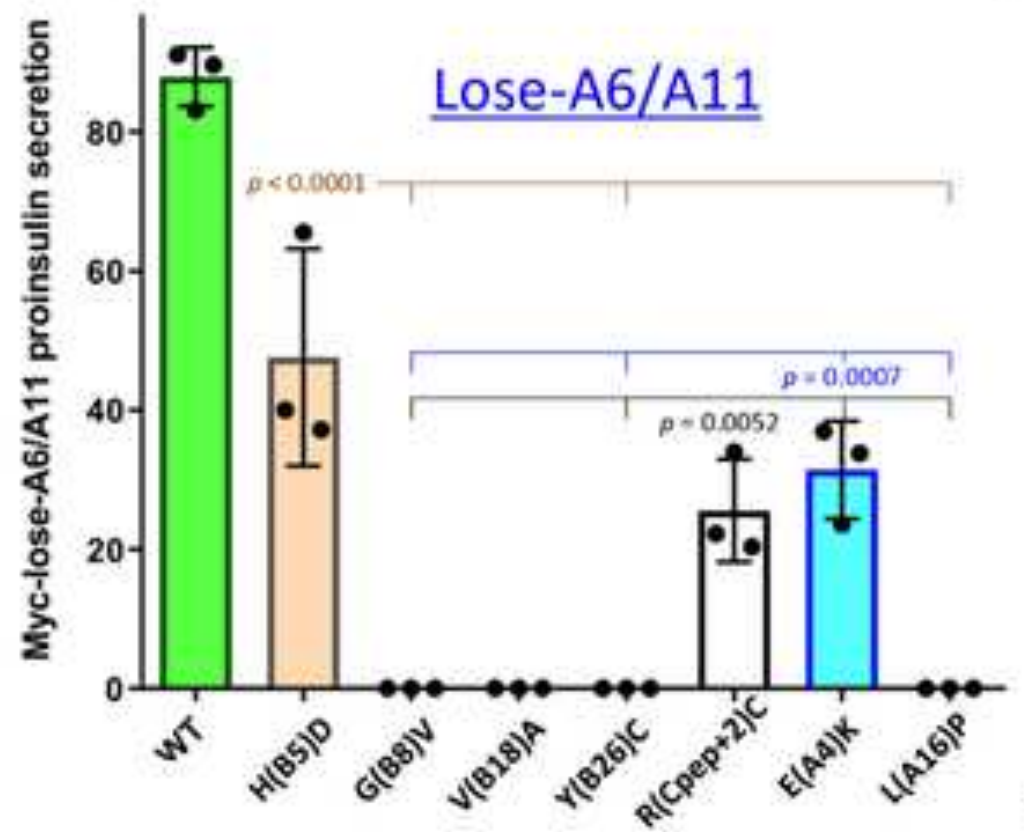

Haataja, Arunagiri et al., Fig. 8

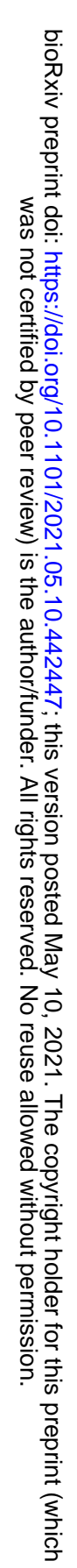

